\title{
ESTIMATING DIELECTRIC PERMITTIVITY AND ELECTRIC CONDUCTIVITY FROM SIMULATED MULTICHANNEL GPR PULSES USING ACO AND QUASI-NEWTON INVERSION TECHNIQUES
}

\author{
Maria da Graça Gomes ${ }^{1}$, Roberto Pinto Souto², Alexandre Sacco de Athayde ${ }^{3}$, \\ Marco Túllio Menna Barreto de Vilhena ${ }^{4}$ and Adelir José Strieder ${ }^{5}$
}

\begin{abstract}
Inversion of synthetic ground-penetrating radar data to estimate both dielectric permittivity $(\varepsilon)$ and electric conductivity $(\sigma)$ properties simultaneously is presented in this paper. The synthetic Ground-Penetrating Radar (GPR) data was generated by the propagation of a one-dimensional electromagnetic wave (1-D EM wave) through a given geological model. The simulated EM trace was modeled by Finite Difference Time Domain method (FDTD) for three different frequencies $(f)$ : 800,1000 and $1200 \mathrm{MHz}$. Random noise was also introduced to evaluate inversion algorithm performance. The inversion of GPR data was performed by Ant Colony Optimization (ACO) and Quasi-Newton (QN) techniques. A modified ACO technique was applied to approximate conductivity for deepest positions, and to increase the accuracy and convergence along lower positions. The inversion techniques were able to estimate simultaneously the dielectric permittivity and electric conductivity from synthetic multi-frequency GPR data. The estimated electrical parameters can be used to derive a set of physical properties and to develop a better understanding of the underground geological or geotechnical media.
\end{abstract}

Keywords: ground-penetrating radar, inversion of GPR data, Ant Colony Optimization, Quasi-Newton technique.

RESUMO. Neste artigo apresenta-se o registro das ondas eletromagnéticas refletidas (dados sintéticos) e o uso deste registro em algoritmos de inversão que procuram estimar simultaneamente as propriedades permissividade elétrica $(\varepsilon)$ e condutividade elétrica $(\sigma)$. Os dados GPR sintéticos foram gerados pela propagação da onda unidimensional através de um determinado modelo geológico. 0 traço da onda eletromagnética (OEM) simulado foi modelado pelo método das diferenças finitas no domínio do tempo (FDTD) para três diferentes frequências $(f$ ): 800, 1000 e $1200 \mathrm{MHz}$. Os ruídos randômicos foram introduzidos para verificar a performance do algoritmo de inversão. Os dados de inversão GPR (permissividade dielétrica e condutividade elétrica) foram obtidos pelos métodos Ant Colony Optimization (Otimização da Colônia de Formigas) (ACO) e Quasi-Newton (QN). 0 método ACO modificado foi aplicado para aproximar a condutividade em posições mais profundas e aumentar a precisão e a convergência ao longo da profundidade. Os métodos de inversão foram capazes de estimar simultaneamente duas propriedades do modelo geológico: a permissividade elétrica e a condutividade elétrica para levantamentos georradar multicanais. Os parâmetros elétricos estimados podem ser usados para derivar um conjunto de propriedades físicas e melhorar a compreensão dos meios geológico-geotécnicos em subsolo.

Palavras-chave: radar de penetração no solo, inversão de dados GPR, Otimização da Colônia de Formigas, método Quasi-Newton.

\footnotetext{
1 Universidade FEEVALE, Instituto de Ciências Exatas e Tecnológicas, ERS 239, 2755, Bairro Vila Nova, 93352-000 Novo Hamburgo, RS, Brazil. Phone/Fax: +55(51) 3586-8800 - E-mail: mariag@feevale.br

2 Laboratório Nacional de Computação Científica (LNCC), Av. Getúlio Vargas, 333, Sala 2C-04, Quitandinha, 25651-075 Petrópolis, RJ, Brazil. Phone: +55(24) 22336027 - E-mail: rpsouto@Incc.br

3 Universidade Federal de Pelotas, Instituto de Física e Matemática, Campus Universitário Capão do Leão, s/n, 96010-900 Pelotas, RS, Brazil. Phone: +55(53) 32757346 - E-mail: alexandre.athayde@ufpel.edu.br

${ }^{4}$ Universidade Federal do Rio Grande do Sul, Programa de Pós-Graduação em Matemática Aplicada e Pós-Graduação em Engenharia Mecânica, Av. Bento Gonçalves, 9500, Agronomia, 91509-900 Porto Alegre, RS, Brazil. Phone: +55(51) 3308-3384; Fax: +55(51) 3308-3412 - E-mail: mtmbvilhena@gmail.com

5 Universidade Federal de Pelotas, Laboratório de Modelagem Ambiental e Geológica (MODELAGE-CEng-UFPEL), Centro de Engenharias - Engenharia Geológica e Engenharia de Petróleo, Praça Domingos Rodrigues, 2, Bairro Porto Pelotas, 96010-440 Pelotas, RS, Brazil - E-mail: adelir.strieder@ufpel.edu.br
} 


\section{INTRODUCTION}

Ground-Penetrating Radar (GPR) has been a widely used geophysical technique since the 1990's. As a geophysical tool, GPR is an indirect, non-invasive technique for high-resolution imaging of thin civil structures and shallow subsurface of soils and rocks (Davis \& Annan, 1989). The foundation of GPR images is the effect of electromagnetic wave (EMw) propagation through an existing media structure (cause). GPR images, then, result from the interaction of EMw and physical properties of different components of the investigated structure, as well as the EMw propagation phenomena (e.g., reflection, refraction, diffraction, or polarization).

GPR techniques were improved, last decade, by multichannel equipment and surveys. This technique was developed to image a geological or geotechnical profile in a quicker and easier way, to construct three dimensional images (3-D) (e.g. Lutz \& Perroud, 2006), and to reach different investigation depth at the same surveying (e.g. Manacorda et al., 2002). Some of the multichannel GPR applications are devoted to high-way and rail-road stratigraphic and structural investigations.

The high-way and rail-road GPR surveys are used to estimate dielectric permittivity or signal velocity of constitutive pavement layers. These parameters are important to 1) calculate the correct layer thickness, 2) determine asphalt's air void content, 3) calculate the layer moisture content, 4) estimate the moisture susceptibility and sensitivity related to permanent deformation of unbound materials and other parameters as discussed by Saarenketo (2009). The moisture content is one of the most important parameters, which is related to pavement deformation and degradation in tropical high-ways.

The classical methods to determine the dielectric permittivity of pavements, while furnishing precise results, are time consuming (see Saarenketo, 2009; for a review on this subject). The reference drill core dielectric measurements are used for backcalculating the dielectric permittivity along ground-coupled profiles. The surface reflection method, on the other hand, is applied for air-coupled survey systems. Common mid-point surveys are also used to estimate velocity and dielectric permittivity of the underground layers. These parameters can be obtained by imaging the same survey profile with different antenna separation; consequently, these GPR data can be processed using the same method that is applied for seismic reflection (Fisher et al., 1992; Davis et al., 1994; Bradford, 2006).

The analysis and processing of multi off-set GPR data were improved for site investigations (e.g. Bangbing et al., 2006; Bradford, 2008). The advent of multichannel GPR acquisitions enabled refinements on the data processing of dielectric permittivity, re- flector depth and average soil-water content parameters (Gerhards et al., 2008; Westermann et al., 2010; Wollschläger et al., 2010).

It should be noted, however, that physical parameters such as void, moisture, and water content, porosity and density are all derived from dielectric permittivity determinations. For high frequency surveys and tropical conditions, however, water content and the amount of dissolved ions present in pores and voids contribute significantly to electric conductivity and signal attenuation as imaginary component of EM field is increased. Velocity determination then takes a more complex form, as discussed by Cassidy (2009):

$$
v=\frac{c}{\left\{\mu \varepsilon / 2\left[\sqrt{1+(\sigma / \omega)^{2}}\right]+1\right\}^{1 / 2}}
$$

where $v$ is velocity, $c$ is EM wave velocity in free space, $\mu$ is magnetic permeability, $\varepsilon$ is relative dielectric permittivity, $\sigma$ is electric conductivity and $\omega$ is angular frequency.

The simultaneous estimation of both electric permittivity and conductivity can improve determinations of geotechnical and geological parameters at a given survey place. Such estimation can be performed by solving inverse problems (Campos Velho et al., 2007).

Data inversions have also been increasingly applied to estimate the underground physical parameters from EM field and wave. Initial attempts to invert electromagnetic profiles combining the FDTD method and non-linear optimization model were developed by Umashankar et al. (1994), and Strickel et al. (1994). Campos Velho \& Ramos (1997) estimated electric conductivity distribution from electromagnetic ground data using numerical inversion. Souto et al. (2006) applied Ant Colony Systems to reconstruct absorption and scattering coefficients along vertical profiles. Paasche et al. (2008) applied a cooperative zonal inversion method for georadar and ultrasounds traveltime data in order to locate voids.

This paper aims to present the results of inverting synthetic multi-frequence ground-penetrating radar data. The inverse problem was designed to estimate the properties of both dielectric permittivity $(\varepsilon)$ and electric conductivity $(\sigma)$ at the same time. The inversion was performed throughout an optimization algorithm, taking minimum entropy criteria for regularization (Campos Velho \& Ramos, 1997), and using synthetic data from three simultaneous frequency channels $(f): 800,1000$ and $1200 \mathrm{MHz}$. The objective function for inversion was obtained by the quadratic difference between $E^{\exp }$ and $E^{\text {mod }}$, and minimized using a stochastic algorithm, the heuristic Ant Colony (Dorigo et al., 1996). Further approximations of electric properties $(\varepsilon, \sigma)$ were obtained by applying Quasi-Newton method and a modified Ant Colony Optimization (ACO) algorithm. 


\section{DIRECT METHOD: GENERATING SYNTHETIC EM WAVE THROUGH FDTD MODELING}

The 1-D modeled GPR EM field was generated through solving the Maxwell equations by means of a semi-analytical method (FDTD) (Yee, 1966; Taflove, 1995; Irving \& Knight, 2006). This field avoids some of the undesired phenomena of wave propagation (e.g., diffraction, modulation) that can introduce signal disturbance in this first investigation. The EM field simulations were performed in a stratified model composed of four media domains (Fig. 1). The first stratum is the air layer between the soil and the GPR antenna to simulate unshielded, uncoupled antennas (horn antennas of road-radar systems). The following strata are composed of sandstone, basalt and shale, whose properties are described in Figure 1. These lithologies are used in the layered structure because there is no determination of electrical properties in common Brazilian pavement material. These materials approximately account for expected electrical properties contrast. The EMw traces were then obtained for three frequencies $(800,1000$ and $1200 \mathrm{MHz}$ ) at same layered structure and position, simulating a multi-channel data acquisition.

The spatial domain for FDTD EM field simulation is described in 16 positions. The first three spatial positions are referred to the air layer, whose electrical properties are well known. The sandstone layer uses the following seven positions, the basalt layer uses three positions, and finally the deepest three positions are used by shale layer (Table 1). Therefore, only 13 layered pavement positions are estimated for $\varepsilon$ and $\sigma$ parameters during data inversion investigation, giving rise to $26(\varepsilon \sigma)$ unknown values.

Table 1 - FDTD parameters for the direct numerical modeling of GPR EM field.

\begin{tabular}{|c|c|}
\hline Parameter & Input value \\
\hline Space increment $(\mathrm{d} x)$ & $4 \times 10^{-2} \mathrm{~m}$ \\
Time increment $(\mathrm{d} t)$ & $1.33 \times 10^{-10} \mathrm{~s}$ \\
GPR antenna frequencies $(f)$ & $800,1000,1200(\mathrm{MHz})$ \\
Spatial discretization $(n x)$ & 16 \\
Time iterations $(n y)$ & 200 \\
Size of spatial domain $(D)$ & $64 \times 10^{-2} \mathrm{~m}(16 \times \mathrm{d} x)$ \\
Air layer & $12 \times 10^{-2} \mathrm{~m}(3 \times \mathrm{d} x)$ \\
Layer 1 thickness & $28 \times 10^{-2} \mathrm{~m}(7 \times \mathrm{d} x)$ \\
Layer 2 thickness & $12 \times 10^{-2} \mathrm{~m}(3 \times \mathrm{d} x)$ \\
Layer 3 thickness & $12 \times 10^{-2} \mathrm{~m}(3 \times \mathrm{d} x)$ \\
\hline
\end{tabular}

\section{INVERSION TECHNIQUES: PRESENTATION OF THE APPLIED METHODS}

In this paper, two different inversion techniques were applied: a) Ant Colony Optimization (ACO) (see Campos Velho et al., 2007; for a revision), and b) Quasi-Newton technique. The first one is stochastic method, based on input data and on objective-function convergence, while the second one is a deterministic method based on linear equation system solution. Stochastic methods are time consuming and computationally hard, but converge to global solution. Deterministic methods, on the other hand, can rapidly converge to a local solution.

These inversion techniques were applied sequentially. The ACO method showed to be efficient to estimate the best approximation for inverted $\varepsilon$ and $\sigma$ parameters. The Quasi-Newton technique, on the other hand, showed to be efficient to find an approximate solution even when initial $\varepsilon$ and $\sigma$ parameters are set well far from real values. Then, ACO method is applied in a first stage, while Quasi-Newton technique is applied to determine the final solution.

The inverse GPR reflection problem arose when electric properties had to be estimated from measurements of electromagnetic field $(E)$. The set of parameters to be simultaneously estimated is $N_{z}$ discrete values of both dielectric permittivity $(\varepsilon)$, and electric conductivity $(\sigma)$. The search solution is denoted by $x=[\varepsilon \sigma]^{\top}$.

The inversion is formulated according to an implicit approach (Lamm, 1993). The algorithm is expressed as a constrained nonlinear optimization problem, in which the FDTD modeled GPR trace is iteratively solved by successive approximations for unknown parameters. The iteration proceeds until an objective-function converges to a specified small value; it represents the least-squares fit of model results and experimental data added by a regularization term (Souto et al., 2007).

The inversion process showed that input data volume (a single frequency) is not sufficient to solve the amount of needed information. Hence, the input data are the electromagnetic fields (E) for three different frequencies $(f)$ : 800, 1000 and $1200 \mathrm{MHz}$. The iteration process takes into account all 3 frequencies at the same time.

The experimental data are discrete electromagnetic fields

$$
E^{\exp }\left(z_{i}, t_{j}, \text { freq }_{k}\right)
$$

where $i=1,2, \ldots, N_{z}, j=1,2, \ldots, N_{t}$, and $k=$ $1,2, \ldots, N_{\text {freq }}, z_{i}$ are depths, $t_{l}$ are times, freq $q_{k}$ are frequencies, $N_{\text {freq }}$ are discrete values of frequency. The $N_{z}$ discrete values of $\varepsilon$ and $\sigma$ are estimated from $1 \times N_{t} \times N_{\text {freq }}$ spectral electromagnetic field values right at the receiving antenna. The objective function $J(\mathbf{x})$ is given by the square dif- 


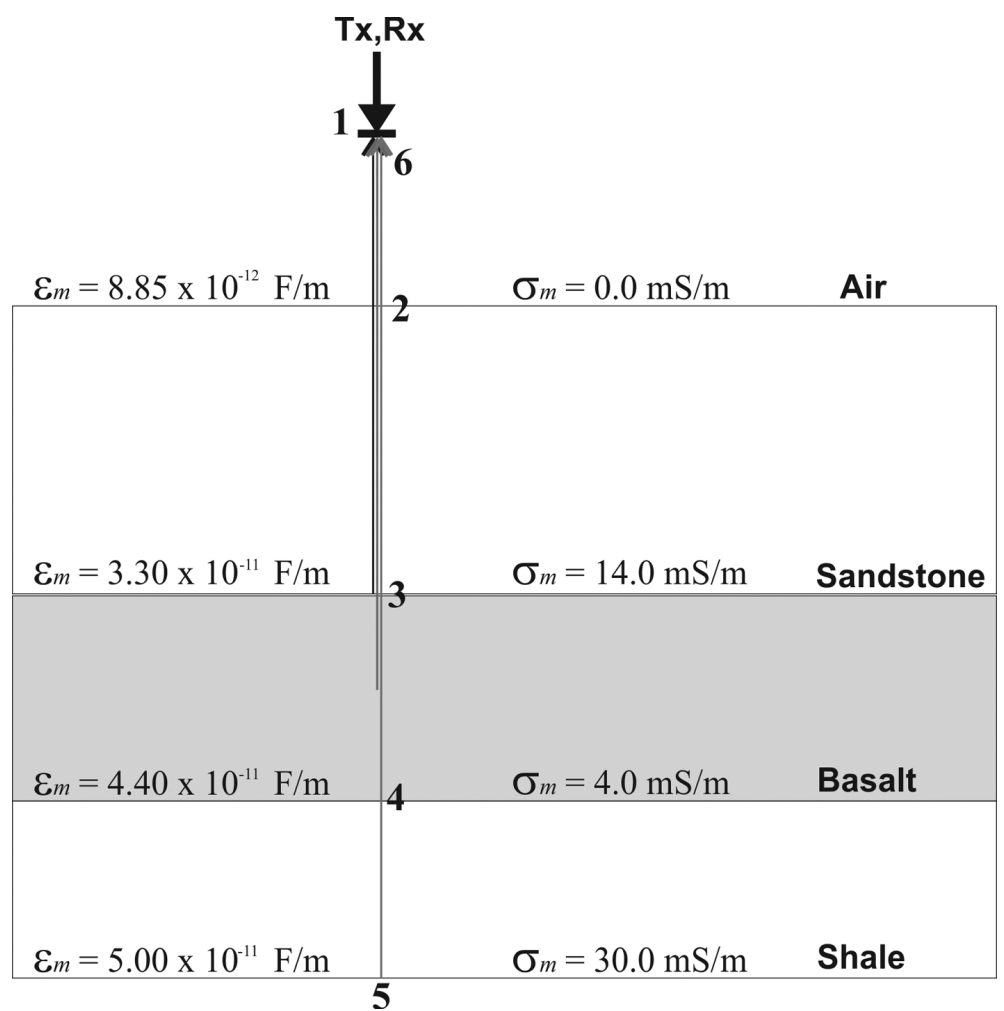

Figure 1 - Layered structure used to determine EMw traces through 1-D FDTD numerical modeling. (1) GPR pulse source. (2) Interface between air and sandstone layers. (3) Interface between sandstone and basalt layers. (4) Interface between basalt and shale layers. (5) GPR reflected pulse at the end of the domain. (6) GPR signal received after transmission, reflections and refraction.

ference between experimental and FDTD modeled fields plus a regularization term:

$$
\begin{gathered}
J(\mathbf{x}) \sum_{l=1}^{N_{t}} \sum_{k=1}^{N_{\text {freq }}}\left[E^{\exp }\left(0, t_{l} \text { freq }_{k}\right)\right. \\
-E^{\bmod }\left(0, t_{l}, \text { freq }_{k}\right)^{2}+\gamma[S(\varepsilon) S(\sigma)]
\end{gathered}
$$

where $E^{\exp }$ are experimental modeled fields and $E^{\text {mod }}$ are FDTD modeled fields, $S(\varepsilon)$ and $S(\sigma)$ are regularization functions, which are weighted by a regularization parameter $(\gamma)$. In this work, the first-order Minimum Entropic regularization was chosen (Tikhonov \& Arsenin, 1977), which may be defined by:

$$
\begin{gathered}
S(\mathbf{x})=-\sum_{i=1}^{N_{z}} q_{i} \log _{10} q_{i} \\
q_{i}=\frac{p_{i}}{\sum_{i=1}^{N_{z}} p_{i}} \\
p_{i}=\left|x_{i+1}-x_{i}\right|+\zeta \quad i=1, \ldots, n-1
\end{gathered}
$$

where $q_{i}$ and $p_{i}$ are probability and first-order discrete difference operator, respectively; $\zeta$ is a constant $(0<\zeta<<1)$ introduced mainly to calculate the $p_{i}$ value different from 0 .

\section{Ant Colony Optimization}

Ant Colony Optimization (ACO) is based on the collective behavior of ants to choose a path between the nest and the food source (Dorigo et al., 1996). Each ant marks its path with an amount of pheromone, and the marked path is further employed by other ants as a reference. In the ACO method, several generations with fixed amounts of ants $(n a)$ are produced and evaluated. Each ant is associated to a feasible path that represents a candidate solution. The solution is composed by a particular set of edges on a graph that contain all other possible solutions. The ants are generated by choosing these edges on a probabilistic basis. This approach has been successfully used for the Traveling Salesman Problem (TSP) and other graph-like problems (Dorigo et al., 1996).

In this work, a candidate solution is not associated to the path, but is composed by a set of discrete values that denote 
particular $\varepsilon$ and $\sigma$ depth profiles. These values are randomly chosen for layers below air-road interface. Two discretizations are adopted, since there are ns discrete depths of estimated $\mathbf{x}$ and, for each depth $i, n_{p}$ discrete $j$ values for the deposited pheromone concentration $\left(T_{0}\right)$. Therefore, the candidate solution is composed of $n s$ values and there are $n s \times n p$ possible choices to define it. In this way, the solution is expressed by a $n s$-tuple $[i j]$, and a $T_{i j}$ pheromone matrix is defined with dimension $n s \times n p$. In each generation, all candidate solutions are evaluated by the objective function and the best solution defines the path followed by an ant.

Taking into account the pheromone decay rate $(\rho)$, the total amount of pheromone $\left(T_{i j}\right)$ in a given generation $(t)$ is given by:

$$
T_{i j}(t)=(1-\rho) T_{i j}(t-1) \quad t=1,2, \ldots, \text { mit }
$$

where mit is the maximum number of ants iterations (generations). The initial amount of pheromone was calculated according to Dorigo et al. (1996):

$$
T_{i j}(0)=T_{0}=\frac{1}{n s \cdot Q}
$$

where $Q$ is the objective function value when $\mathbf{x}=[11]^{\top}$. It is to be noted that these $\varepsilon$ and $\sigma$ initial values were set very far from those defined for each lithological layer. They were selected to make the convergence difficult during inversion processing.

The probability of a given path $[i j]$ to be chosen in each ant generation is then

$$
P_{i j}(t)=\frac{\left[T_{i j}(t)\right]^{\alpha}\left[\eta_{i j}(t)\right]^{\beta}}{\sum_{l}\left\{\left[T_{i l}(t)\right]^{\alpha}\left[\eta_{i l}(t)\right]^{\beta}\right\}}
$$

where $l \in[1, n p]$ and $\eta_{i j}$ is the visibility of the path $[i j]$. The visibility concept (Souto et al., 2007) arose from the TSP, and it is the inverse of the distance for a particular path. The parameters $\alpha$ and $\beta$ are weights that establish the influence of the pheromone and the visibility on the $[i j]$ path probability. In this study, $\alpha$ and $\beta$ were set 1.0 and 0.0 respectively, because a distancedependent visibility approach is not applicable to the solution for this type of inverse problem.

Algorithms 1, 2 and 3 describe the complete ACO implementation (Table 2). Table 2a shows the algorithm that evaluated the cost of nap profiles for $\varepsilon$ and $\sigma\left(\mathbf{x}=[\varepsilon \sigma]^{\top}\right)$ in each iteration, were $n a_{p}$ are pre-selected ants in each generation.

There is also a further procedure for choosing the path of a new ant (solution). A random number $\left(r_{0}\right)$ in the range $[0,1]$ is generated for this new ant and compared with a decision parameter $\left(q_{0}\right)$ chosen for the problem. The choice of the most probable discrete value in this work, among all $n p$ values, is disabled in the ACO $\left(q_{0}=0\right)$ method. Thus, the rule of decision to choose each $\mathbf{x}$ solution component is established through comparison on cumulative probability and a random generated number $\left(r_{0}\right)$, according to Table 2c. If the random number is greater than this parameter, the path is taken according to $P_{i j}$; if it is lower, the most marked path is assigned.

\section{Intrinsic regularization}

In the present work, the ACO-based inverse solver with an intrinsic regularization (Souto et al., 2005; Souto et al., 2006) is employed without the regularization term $(\gamma=0)$ shown in Eq. (2).

As a supposed initial flat profile is required, this represents a kind of a priori information about the inverse solution. Such knowledge is included in the generation of candidate solutions by means of pre-selecting the most suitable ants according to the first-order Minimum Entropy regularization (Tikhonov \& Arsenin, 1977). As a stochastic scheme, the ACO dealt as a set of candidate inverse solutions (the population of ants or paths: $n a$ ). The suitableness of each candidate solution is quantified by the Minimum Entropy norm. Only one subset of the candidate inverse solutions, the most suitable one, is selected to be evaluated for the objective function: $n a_{p}$, where $n a_{p}<n a$. The user can define how many inverse solutions will be included in such subset. The pre-selection algorithm is described in Table $2 b$, where, for each $n a / n a_{p}$ generated solution (see Algorithm 3, Table 2c), the most suitable one is chosen. Actually, then, a kind of preregularization is performed. Therefore, the usual regularization term in Eq. (2) is not required.

\section{Modified cost evaluation in ACO}

An enhanced procedure to evaluate the candidate solutions in ACO algorithm (Table 2d) is also implemented in this work (Gomes, 2010). Typically, if there was a change in the underground electrical properties, the GPR pulse would have been split into reflected and transmitted ones. As a consequence, the values of dielectric permittivity $(\varepsilon)$ and electric conductivity $(\sigma)$ in deeper points had eventually a lower influence of the electromagnetic field $(E)$ measured right above the surface when compared to previous media. Therefore, $\varepsilon$ and $\sigma$ in deeper media may be more difficult to estimate due to the reduction in surface electromagnetic field energy and due to mistakes generated by the explicit FDTD method that spread it throughout time. 
The cost of each candidate solution, nevertheless, is still calculated according to the traditional method (Algorithm 1 in Table 2a). Actually, all combinations of the candidate solutions are evaluated, one by one. For instance, the second $\left(\mathbf{x}_{2}=\right.$ $\left.\left[\varepsilon_{2} \sigma_{2}\right]^{\top}\right)$ and fifth $\left(\mathbf{x}_{5}=\left[\varepsilon_{5} \sigma_{5}\right]^{\top}\right)$ solutions are combined to produce $\left(\mathbf{J}\left(\left[\varepsilon_{2} \sigma_{5}\right]^{\top}\right)\right.$ and $\left(\mathbf{J}\left(\left[\varepsilon_{5} \sigma_{2}\right]^{\top}\right)\right.$ values. The procedure is performed for all $n a_{p}$ solutions, as described in Algorithm 4 (Table 2d).

In order to better estimate $\varepsilon$ and $\sigma$ in deeper media, an alternative method was then performed (Gomes, 2010). It defines the candidate solutions $\left(\mathbf{x}=[\varepsilon \sigma]^{\top}\right)$ according to the values of the objective function Eq. 2), but with more rigorous criteria. In the first step, both $(\varepsilon \sigma)$ parameters are estimated through modified ACO method. In the second step, the $(\varepsilon \sigma)$ parameters are then refined by the Quasi-Newton method. The ACO algorithm is able to make a good estimation for $(\varepsilon \sigma)$ parameters mainly for shallow deeps, even when the initial $[\varepsilon \sigma]^{\top}$ parameters are set $[11]^{\top}$ well distant from the values given in the direct FDTD method.

It was realized that ACO algorithm (Table 2a) could not approximate both $(\varepsilon \sigma)$ parameters at the same time for deeper positions due to loss of the EM field energy and propagation errors introduced by the explicit FDTD direct method. The QuasiNewton method was then applied to estimate $(\varepsilon \sigma)$ parameter and to define how many positions could keep the same value for those parameters.

The $\varepsilon$ parameter and positions defined through QuasiNewton method are then fixed in the modified ACO algorithm (Table 2d) in order to estimate only the $\varepsilon$ parameter. After that, the values of the candidate solution ( $\mathbf{x}$ ) are fixed up to $z=z_{i}$. The procedure is then repeated and the ACO algorithm searches for new $\sigma$ values only for depths greater than $z_{i}$.

\section{Quasi-Newton Inversion Technique}

The Quasi-Newton is a deterministic method designed to solve a system of linear equations, and, then, has low computational cost for implementation. The methodological basis and algorithms for this inversion technique are well known in literature (Dennis \& Schnabel, 1983; Fletcher, 1987). In this work, the FCN_BCONF subroutine from MSIMSL library was implemented in Fortran 90 software (IMSL, 1991).

\section{RESULTS AND DISCUSSIONS ON APPLYING ACO AND QUASI-NEWTON TECHNIQUES UPON SYNTHETIC DATA}

The ACO inversion technique is a stochastic method and, consequently demands excessive computation time. As described above, the inversion technique took approximately nine minutes for each seed in intrinsic regularization and modified cost evaluation in ACO on a sequence computer, Intel Core $2 \mathrm{Duo}, 1.86 \mathrm{GHz}$, $4 \mathrm{~GB}$ of RAM. In this way, different parameters for ACO inversion were quoted. It was realized that fewer ants $(n a)$ save process time; however, lower quality results are obtained. Moreover, once the decision parameter value $\left(q_{0}\right)$ is increased, a higher algorithm convergence rate is obtained, in spite of resulting in a worse solution. Yet, when the smallest decay rate is chosen, more iteration is necessary to converge a solution. On the other hand, this solution was of better quality most of time.

The number of positions ( $n s)$ and distance $(\mathrm{d} x)$ for $\varepsilon$ and $\sigma$ parameters estimation were chosen taking into account i) the pulse range of each antenna frequency, ii) vertical resolution and iii) stability conditions of the FDTD method. The first one is directly associated to pulse attenuation while it moves to deeper subsoil (Parasnis, 1997). Each frequency has a different loss of energy and penetration depth, so that the profile under estimation needs to accomplish all frequencies. The second factor is related to size of identifiable object to each pulse return. According to Parasnis (1997), the size of distinguishable objects is about $1 / 4$ of wavelength. In the source code, these ideas were implemented using different $n, n a$ and $n a_{p}$ values. The final parameter configurations for ACO inversion (Table 3) were: i) a pilot sample $(n=16)$ was taken, assuming significance level of 0.03 and estimative error of 0.13 ; ii) $m i t=500, n a=20$ and $n a_{p}=4$. In all simulations, the maximum iterations number were not more than 500 to stabilize the cost of objective function.

The aim of this section is to build up a geophysical model from synthetic GPR data (Gomes, 2010). The estimated results for $\varepsilon$ and $\sigma$ parameters compare modeled GPR data with and without noise in order to evaluate the performance of the inversions algorithms. The noise was introduced in order to evaluate the Inversion Technique capability in recovering the values for both $\varepsilon$ and $\sigma$ parameters. To better evaluate the statistical significance of the estimated $\varepsilon$ and $\sigma$ parameters, the number of positions for inversion were set equal to that for producing FDTD synthetic GPR data $(n=16)$.

\section{GPR data without noise}

The inversion of synthetic GPR data includes only previous regularization (Intrinsic regularization) and modified ACO algorithms (Modified cost evaluation in ACO) to obtain estimated permittivity and conductivity profile results (Gomes, 2010). The obtained results for the first set of simulations throughout algorithms 1, 2, 
Table 2 - Algorithms for estimating dielectric permittivity and electric conductivity in modeled GPR data. (a) Algorithm for Ant Colony Optimization process (1). (b) Intrinsic regularization algorithm (2) to evaluate candidate solutions according to first-order Minimum Entropy norm. (c) ACO solution (x) algorithm (3) based on cumulative path probabilities. (d) Modified ACO-based algorithm (4) to evaluate the cost of $n a \times n a_{p}$ combinations of $\varepsilon$ and $\sigma$ in each iteration solution $\left(\mathbf{x}=[\varepsilon \sigma]^{\top}\right)($ Gomes, 2010).

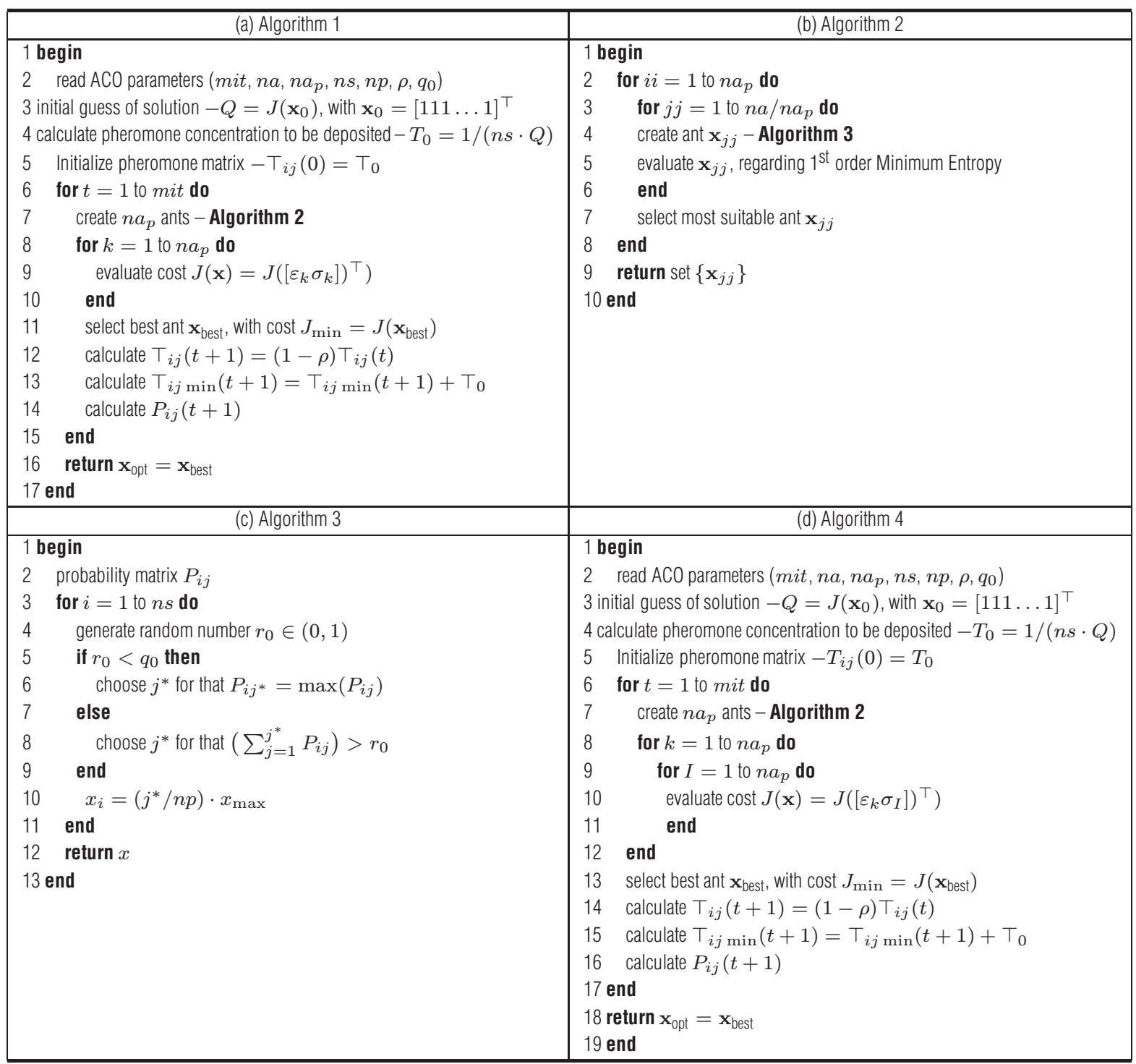

where $\mathbf{x}_{0}$ is initial guess solution, $\mathbf{x}_{\text {best }}$ is best ant, and $J_{\min }$ is minimum cost.

Table 3 - ACO inversion parameters and seeds used in algorithms.

\begin{tabular}{|c|c|c|c|c|c|c|c|}
\hline \multirow{2}{*}{ AC0 parameters } & $n s$ & $n p$ & $n a$ & $n a_{p}$ & mit & $\rho$ & $q_{0}$ \\
\cline { 2 - 8 } & 16 & 20 & 20 & 4 & 500 & 0.03 & 0.0 \\
\hline Seeds (10) & \multicolumn{6}{|c|}{$17,19,23,31,35,41,43,57,61,79$} \\
\hline
\end{tabular}

and 3 (Table 2) can be found in Figure 2. Note that the first three positions are not inverted, because they represent the air layer, where EM pulse was generated. The $\varepsilon$ and $\sigma$ parameters for air, as well as antenna height during survey, are known parameters.
The estimated values for $\varepsilon$ and $\sigma$ parameters were not satisfactory. It should be remembered that it is necessary to determine simultaneously 26 unknown values. The ACO methodology allowed a better estimation for dielectric permittivity (mean 


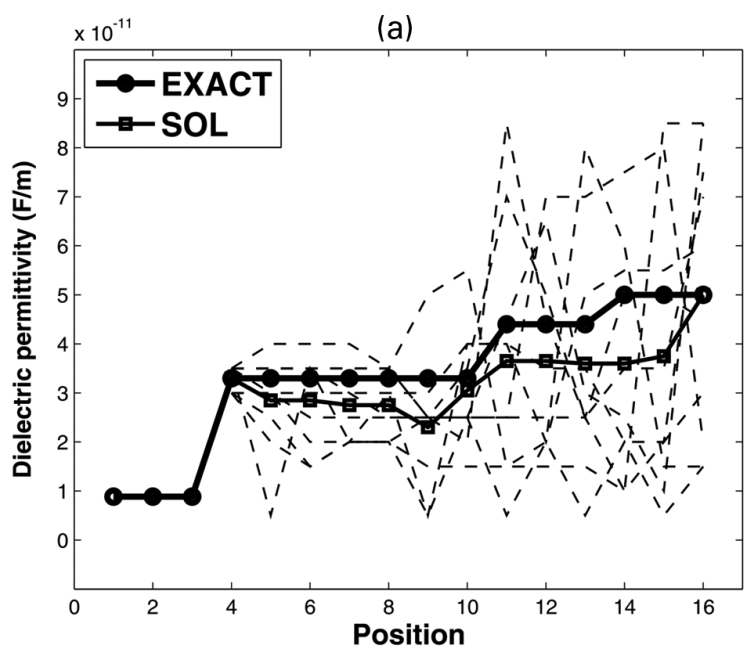

(b)

Figure 2 - Simultaneous estimated values for $\varepsilon$ (a) and $\sigma$ (b) parameters using ACO algorithm compared with model GPR data. Results after 500 iterations and minimum entropy regularization criterion, applied on GPR data without noise. EXACT refers to original value used in generating synthetic data (Real value in Fig. 1). SOL refers to estimated value from inversion technique (estimated value on Tables 4 and 5 ).

values) than for electric conductivity (mean values) as can be seen in Figure 2.

The deterministic Quasi-Newton (QN) method was chosen in order to improve the estimation for both $\varepsilon$ and $\sigma$ parameters, as discussed in Modified cost evaluation in ACO above. Figure 3 presents the results for dielectric permittivity and conductivity profiles obtained after applying the Quasi-Newton inversion method, and shows a better estimation for both $\varepsilon$ and $\sigma$ parameters when compared to Figure 2 results. The $\varepsilon$ values were im- proved after applying Quasi-Newton inversion method. However, the electric conductivity was not improved.

Next, the estimated $\varepsilon$ values were fixed from 4st to 16th position and modified ACO Algorithm 4 (Table 2d) was run in the next step to estimate only the unknown $\sigma$ values. Figure 4 represents the results of this step, and shows that estimated values for $\sigma$ parameter are closer to values introduced in the FDTD modeling. In the first step, the $\sigma$ values of the first nine positions were fixed, and the modified ACO inversion algorithm (Table 2d)

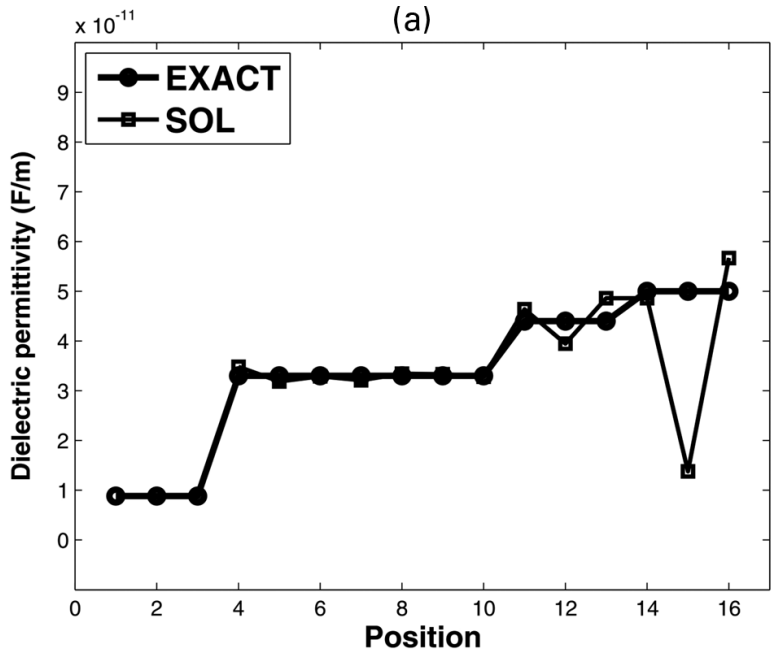

(b)

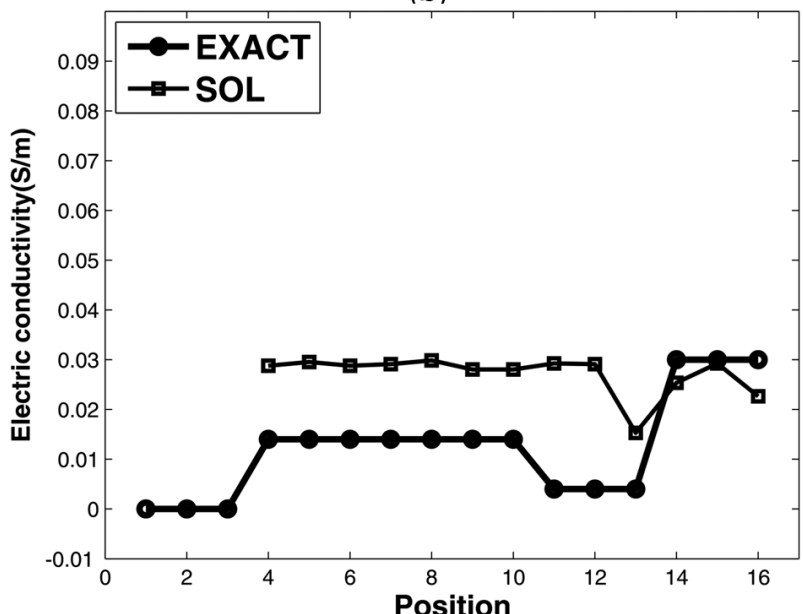

Figure 3 - Simultaneously estimated values for $\varepsilon$ (a) and $\sigma$ (b) parameters, considering the ACO results (Fig. 2) as an "initial guess" for Quasi-Newton method. Modeled GPR data without noise. EXACT refers to original value used in generating synthetic data (Real value in Fig. 1). SOL refers to estimated value from inversion technique (estimated value on Tables 4 and 5). 


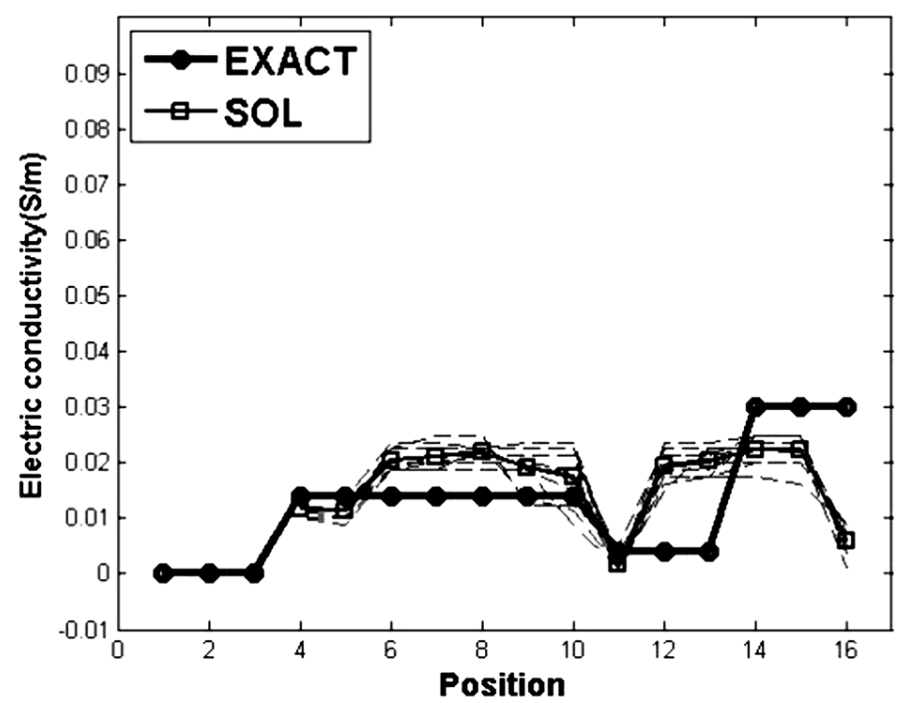

Figure 4 - Estimated values for $\sigma$ parameter after running the modified ACO algorithm (first run), and considering the fixed $\varepsilon$ values. GPR modeled data without noise. EXACT refers to original value used in generating synthetic data (Real value in Fig. 1). SOL refers to estimated value from inversion technique (estimated value on Tables 4 and 5 ).

was run. In the next step, the $\sigma$ values of the first ten positions were fixed. The process was repeated until the 16 th position was estimated.

Figure 5 shows the results for the second run (10th position, Fig. 5a) and for the last run (16th positions, Fig. 5b). It should be noted that ACO inversion parameters remain the same as shown in Table 3 above. Also in Figure 5, the electric conductivity values approximate the exact profile for the first eight positions (4th to 11th), but does not for the last five positions (12th to 16th). This is probably due to errors introduced by the explicit FDTD method used to simulate the EM wave; or else due to energy loss of the EM wave propagating to deeper geological structure.

A statistical analysis compares real values for $\varepsilon$ and $\sigma$ parameters (defined to generate synthetic data) and estimated values after inversion (data presented in Figs. 2, 3, 4, and 5). Tables 4 and 5 presents, respectively, the statistical analysis for estimated $\varepsilon$ (a)

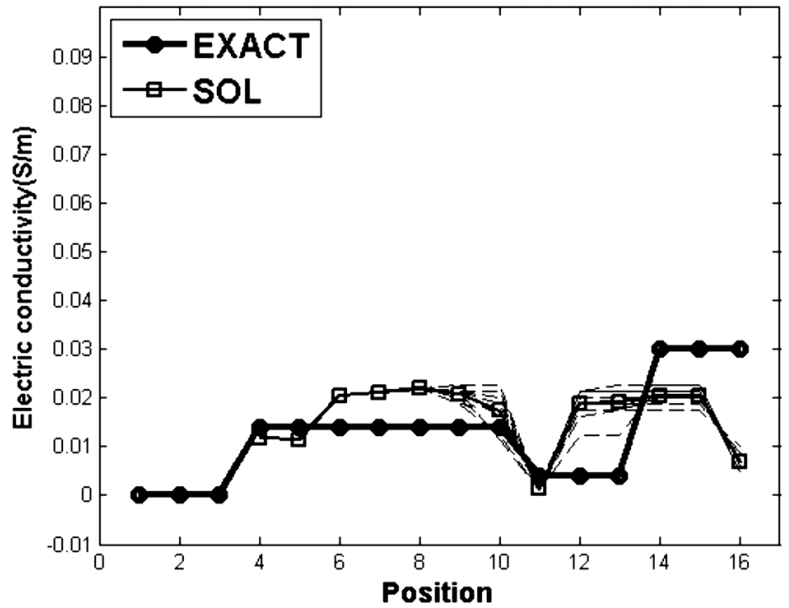

(b)

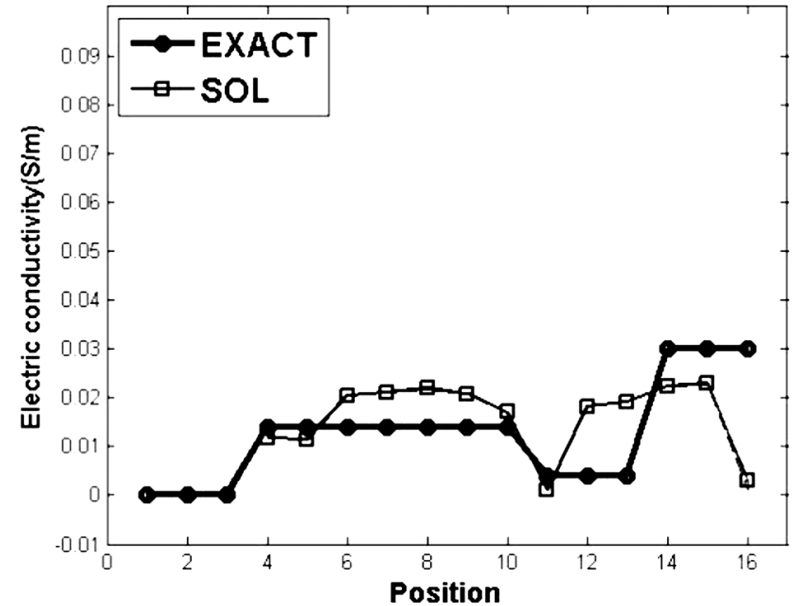

Figure 5 - Estimated values for $\sigma$ parameter using the modified ACO inversion algorithm. The conductivity is fixed (a) from 4th to 9th position in the second run, and (b) from 4th to 15th position for the last run. GPR modeled data without noise. EXACT refers to original value used in generating synthetic data (Real value in Fig. 1). SOL refers to estimated value from inversion technique (estimated value on Tables 4 and 5). 
Table 4 - Statistical evaluation of $\varepsilon$ property estimated for GPR modeled data without noise considering $97 \%$ confidence interval. ( ${ }^{*}$ ) indicates that values are outside $97 \%$ confidence interval. Lower and Upper limits represent the lowermost and uppermost estimated value according inversion technique.

\begin{tabular}{|c|c|c|c|}
\hline $\begin{array}{c}\text { Real values } \\
(\varepsilon)\end{array}$ & $\begin{array}{c}\text { Lower } \\
\text { limit }\end{array}$ & $\begin{array}{c}\text { Mean estimated } \\
\text { value }\end{array}$ & $\begin{array}{c}\text { Upper } \\
\text { limit }\end{array}$ \\
\hline $3.30 \times 10^{-11}$ & $2.9849 \times 10^{-11}$ & $3.4810 \times 10^{-11}$ & $3.9771 \times 10^{-11}$ \\
$3.30 \times 10^{-11}$ & $2.7182 \times 10^{-11}$ & $3.2143 \times 10^{-11}$ & $3.7104 \times 10^{-11}$ \\
$3.30 \times 10^{-11}$ & $2.7731 \times 10^{-11}$ & $3.2692 \times 10^{-11}$ & $3.7653 \times 10^{-11}$ \\
$3.30 \times 10^{-11}$ & $2.7365 \times 10^{-11}$ & $3.2326 \times 10^{-11}$ & $3.7287 \times 10^{-11}$ \\
$3.30 \times 10^{-11}$ & $2.7439 \times 10^{-11}$ & $3.2400 \times 10^{-11}$ & $3.7361 \times 10^{-11}$ \\
$3.30 \times 10^{-11}$ & $2.8655 \times 10^{-11}$ & $3.3616 \times 10^{-11}$ & $3.8577 \times 10^{-11}$ \\
$3.30 \times 10^{-11}$ & $2.8022 \times 10^{-11}$ & $3.2983 \times 10^{-11}$ & $3.7944 \times 10^{-11}$ \\
$4.40 \times 10^{-11}$ & $4.0054 \times 10^{-11}$ & $4.5015 \times 10^{-11}$ & $4.9976 \times 10^{-11}$ \\
$4.40 \times 10^{-11}$ & $3.9051 \times 10^{-11}$ & $4.4012 \times 10^{-11}$ & $4.8973 \times 10^{-11}$ \\
$4.40 \times 10^{-11}$ & $3.8239 \times 10^{-11}$ & $4.3200 \times 10^{-11}$ & $4.8161 \times 10^{-11}$ \\
$5.00 \times 10^{-11}\left(^{*}\right)$ & $5.0939 \times 10^{-11}$ & $5.5900 \times 10^{-11}$ & $6.0861 \times 10^{-11}$ \\
$5.00 \times 10^{-11}$ & $4.8077 \times 10^{-11}$ & $5.3038 \times 10^{-11}$ & $5.7999 \times 10^{-11}$ \\
$5.00 \times 10^{-11}\left(^{*}\right)$ & $3.9439 \times 10^{-11}$ & $4.4400 \times 10^{-11}$ & $4.9361 \times 10^{-11}$ \\
\hline
\end{tabular}

and $\sigma$ parameters, considering modeled GPR data without noise and the $97 \%$ confidence interval. Tables 4 and 5 show that estimated values agree with initial (real) values determined for generating synthetic data. However, the estimated $\varepsilon$ and $\sigma$ parameters for deepest positions do not agree with real values in the $97 \%$ confidence interval, and this aspect will be addressed later in the paper.

Table $\mathbf{5}$ - Statistical evaluation of $\sigma$ property estimated for GPR modeled data without noise considering $97 \%$ confidence interval. $\left(^{*}\right)$ indicates that values are outside $97 \%$ confidence interval. Lower and Upper limits represent the lowermost and uppermost estimated value according inversion technique.

\begin{tabular}{|c|c|c|c|}
\hline $\begin{array}{c}\text { Real value } \\
(\sigma)\end{array}$ & $\begin{array}{c}\text { Lower } \\
\text { limit }\end{array}$ & $\begin{array}{c}\text { Mean estimated } \\
\text { value }\end{array}$ & $\begin{array}{c}\text { Upper } \\
\text { limit }\end{array}$ \\
\hline $1.40 \times 10^{-2}$ & $5.2635 \times 10^{-3}$ & $1.1375 \times 10^{-2}$ & $1.7487 \times 10^{-2}$ \\
$1.40 \times 10^{-2}$ & $5.1385 \times 10^{-3}$ & $1.1250 \times 10^{-2}$ & $1.7362 \times 10^{-2}$ \\
$1.40 \times 10^{-2}$ & $1.0138 \times 10^{-2}$ & $1.6250 \times 10^{-2}$ & $2.2362 \times 10^{-2}$ \\
$1.40 \times 10^{-2}$ & $1.0763 \times 10^{-2}$ & $1.6875 \times 10^{-2}$ & $2.2987 \times 10^{-2}$ \\
$1.40 \times 10^{-2}$ & $1.1638 \times 10^{-2}$ & $1.7750 \times 10^{-2}$ & $2.3862 \times 10^{-2}$ \\
$1.40 \times 10^{-2}$ & $1.1388 \times 10^{-2}$ & $1.7500 \times 10^{-2}$ & $2.3612 \times 10^{-2}$ \\
$1.40 \times 10^{-2}$ & $9.3885 \times 10^{-3}$ & $1.5500 \times 10^{-2}$ & $2.1612 \times 10^{-2}$ \\
$4.00 \times 10^{-3}$ & $1.3470 \times 10^{-5}$ & $6.1250 \times 10^{-3}$ & $1.2237 \times 10^{-2}$ \\
$4.00 \times 10^{-3}$ & $2.6347 \times 10^{-4}$ & $6.3740 \times 10^{-3}$ & $1.2487 \times 10^{-2}$ \\
$4.00 \times 10^{-3}$ & $3.8847 \times 10^{-4}$ & $6.5000 \times 10^{-3}$ & $1.2612 \times 10^{-2}$ \\
$3.00 \times 10^{-2}$ & $1.8513 \times 10^{-2}$ & $2.4625 \times 10^{-2}$ & $3.0737 \times 10^{-2}$ \\
$3.00 \times 10^{-2}\left(^{*}\right)$ & $1.2513 \times 10^{-2}$ & $1.8625 \times 10^{-2}$ & $2.4737 \times 10^{-2}$ \\
$3.00 \times 10^{-2}\left(^{*}\right)$ & $1.2638 \times 10^{-2}$ & $1.8750 \times 10^{-2}$ & $2.4862 \times 10^{-2}$ \\
\hline
\end{tabular}

\section{Noisy FDTD modeled GPR data}

The following discussion is performed into modeled GPR data where a random noise was introduced. The $\varepsilon$ and $\sigma$ parameters were estimated from modeled GPR data with two levels of noise: $1 \%$ and $5 \%$ noise. It is to noted that inversion techniques is to be applied after filtering procedures in field data; then, these values represent remaining noise after filtering. The geological structure and the frequencies upon which GPR data were modeled are the same as that used for inversion in GPR data without noise. In the same way, inversion procedures are also the same as those used in Ant Colony Optimization, so that one can easily compare the results.

\section{GPR data with $1 \%$ of noise}

Figure 6 shows the results of the ACO inversion method run according discussed in intrinsic regularization above. Figure $6 a$ reveals that mean values for $\varepsilon$ parameter are closer to model value than those for data without noise (Fig. 2a) in the first approximation. On the other hand, estimated values for $\sigma$ parameter (Fig. 6b) do not show changes in this first approximation. These mean values of $\varepsilon$ and $\sigma$ parameters were then set as initial guess for running the Quasi-Newton inversion method.

Figure 7 shows the results of applying Quasi-Newton inversion method taking into account mean values defined by ACO inversion (Fig. 6). It is noticed that of $\varepsilon$ parameter is well fitted to modeled values from the 4th to the 13th position. However, $\sigma$ 

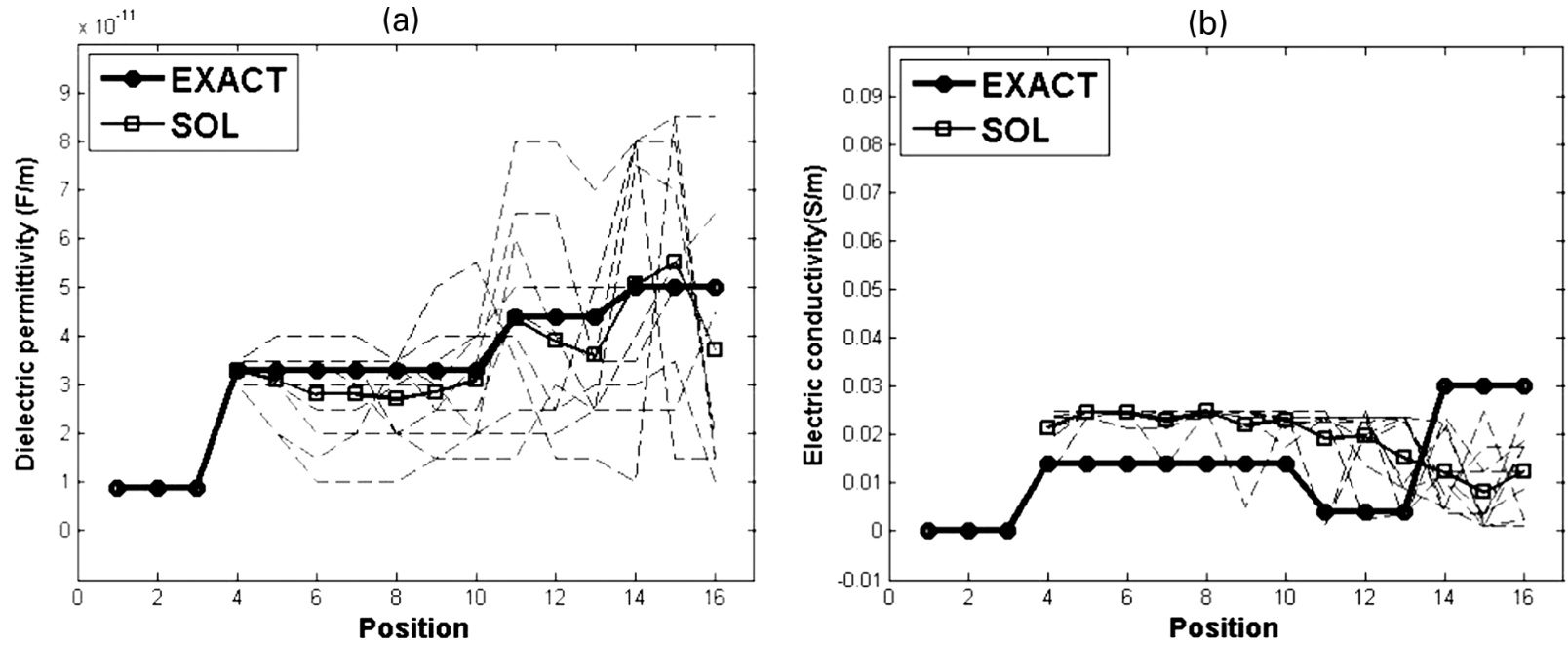

Figure 6 - Simultaneous estimated values for $\varepsilon(\mathrm{a})$ and $\sigma$ (b) parameters using ACO algorithm compared with model GPR data. Results after 500 iterations and minimum entropy regularization criterion, applied on GPR data with $1 \%$ random noise. EXACT refers to original value used in generating synthetic data (Real value in Fig. 1). SOL refers to estimated value from inversion technique (estimated value on Tables 6 and 7 ).
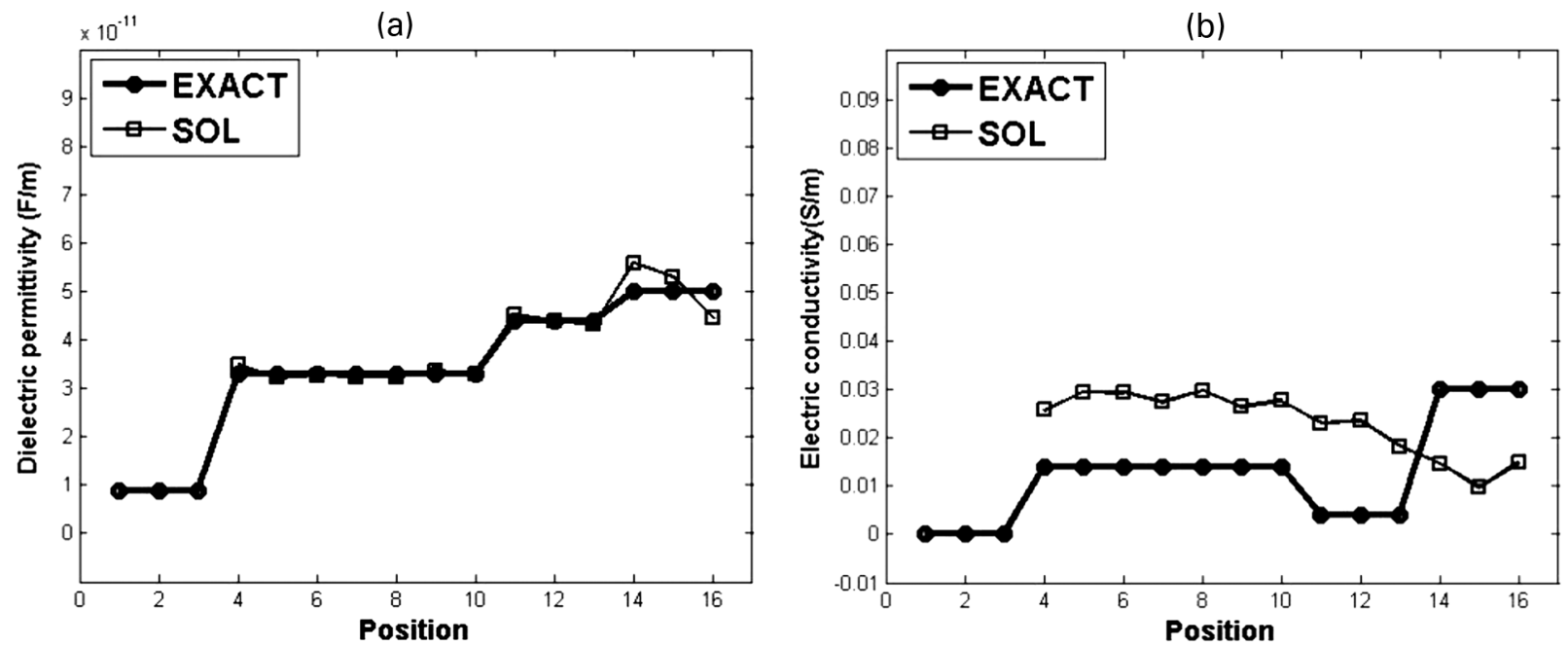

Figure 7 - Simultaneously estimated values for $\varepsilon$ (a) and $\sigma$ (b) parameters, considering the ACO results (Fig. 6) as an "initial guess" for Quasi-Newton method. Modeled GPR data with $1 \%$ of random noise. EXACT refers to original value used in generating synthetic data (Real value in Fig. 1). SOL refers to estimated value from inversion technique (estimated value on Tables 6 and 7 ).

parameter (Fig. 7b) is still far from convergence with modeled values. In this way, the modified ACO inversion algorithm is applied to estimate only the values for $\sigma$; the values for $\varepsilon$ parameter are fixed from 4 th to 16 th position.

Figure 8 presents the results of running ACO inversion to estimate only the $\sigma$ parameter taking into account fixed values for $\sigma$ parameter. The estimated mean values for $\varepsilon$ parameter show a very good improvement when compared with GPR data with no noise (see Fig. 4).
The $\sigma$ parameter for the 9th position is then fixed, and the modified ACO inversion procedure is repeated for positions from 10th to 16th, in the same way that was applied for GPR data without noise. The results for the second and the last run are shown in Figure 9.

The degree of convergence between estimated and modeled (true) values when inverting GPR data with $1 \%$ of random noise should be pointed out. Tables 6 and 7 can be used to evaluate the degree of convergence for $\varepsilon$ and $\sigma$ parameters, respectively. 


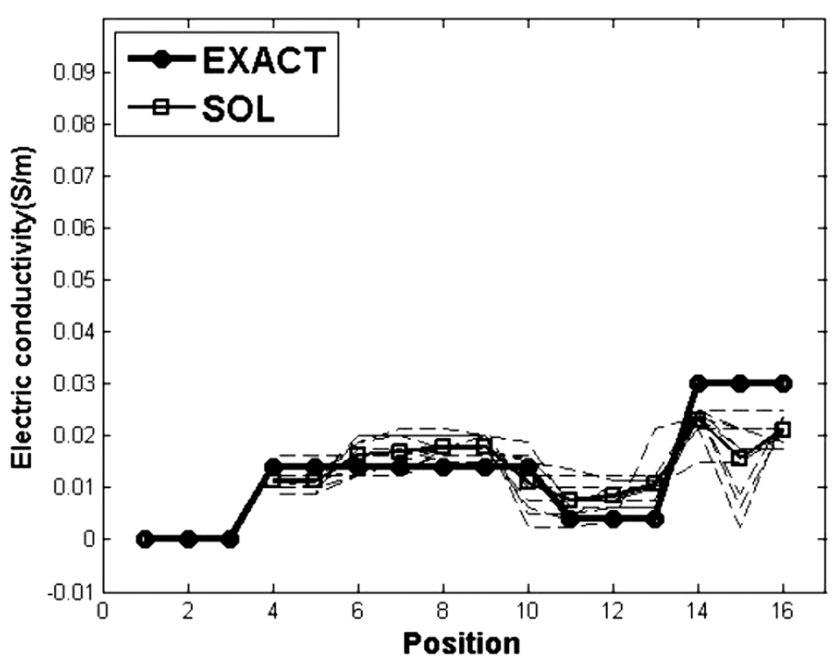

Figure 8 - Estimated values for $\sigma$ parameter after running the modified ACO algorithm (first run), and considering the fixed $\varepsilon$ values. GPR modeled data with $1 \%$ of random noise. EXACT refers to original value used in generating synthetic data (Real value in Fig. 1). SOL refers to estimated value from inversion technique (estimated value on Tables 6 and 7).

(a)

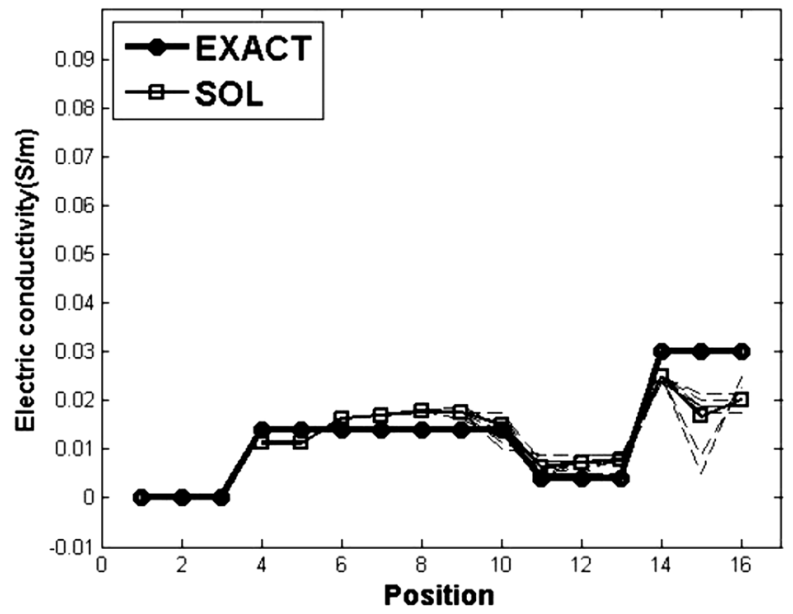

(b)

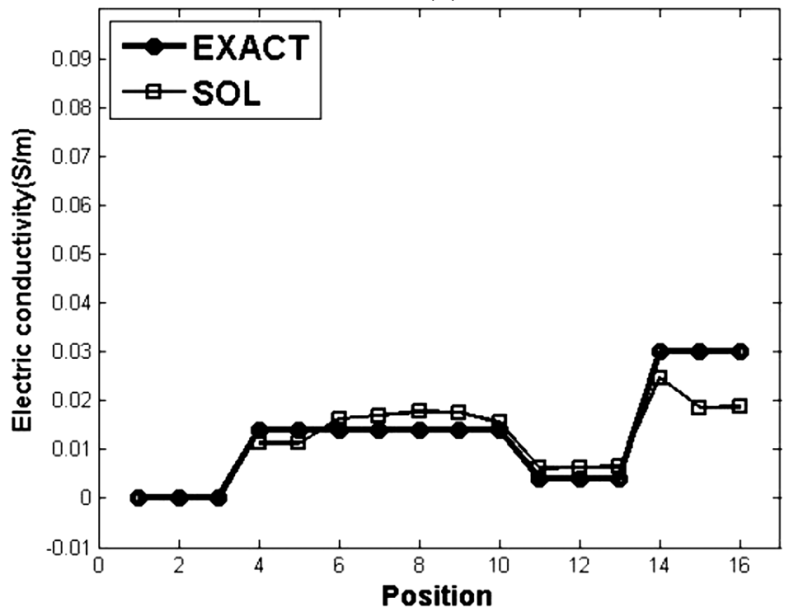

Figure 9 - Estimated values for $\sigma$ parameter using the modified ACO inversion algorithm. The conductivity is fixed (a) from 4th to 9th position in the second run, and (b) from 4th to 15 th position for the last run. GPR modeled data with $1 \%$ of random noise. EXACT refers to original value used in generating synthetic data (Real value in Fig. 1). SOL refers to estimated value from inversion technique (estimated value on Tables 6 and 7).

These statistical analyses show that estimated values agree with true (real, synthetic) values determined for generating synthetic data. However, the estimated $\varepsilon$ and $\sigma$ parameters for deepest positions do not agree with real values in the $97 \%$ confidence interval, and this aspect will be addressed later in the paper.

\section{GPR data with $\mathbf{5} \%$ of noise}

The sequence of procedures for inversion applied in previous section is also used here, but now dealing with modeled GPR data with $5 \%$ of random noise. Figure 10a shows a good first approximation for $\varepsilon$ parameter, despite the differences from position 13th. Figure 10b, like previous correlated figures, does not show good approximation for $\sigma$ parameter values.

These initial mean ACO values were used as initial guess to Quasi-Newton inversion method (see Fig. 11). Figure 11a shows that applying Quasi-Newton inversion method enabled good fitting for the $\varepsilon$ parameter, as noted for inversion of $1 \%$ noise GPR data (Fig. 7a). The convergence problem still remains for estimating $\sigma$ parameter (Fig. 11b). Keeping $\varepsilon$ parameter constant, the modified ACO inversion algorithm is applied for estimating $\sigma$ parameter (Fig. 12). 
Table $\mathbf{6}$ - Statistical evaluation of $\varepsilon$ property estimated for GPR modeled data with $1 \%$ of random noise considering $97 \%$ confidence interval. ${ }^{*}$ ) indicates that values are outside $97 \%$ confidence interval. Lower and Upper limits represent the lowermost and uppermost estimated value according inversion technique.

\begin{tabular}{|c|c|c|c|}
\hline $\begin{array}{c}\text { Real values } \\
(\varepsilon)\end{array}$ & $\begin{array}{c}\text { Lower } \\
\text { limit }\end{array}$ & $\begin{array}{c}\text { Mean estimated } \\
\text { value }\end{array}$ & $\begin{array}{c}\text { Upper } \\
\text { limit }\end{array}$ \\
\hline $3.30 \times 10^{-11}$ & $2.9849 \times 10^{-11}$ & $3.4810 \times 10^{-11}$ & $3.9771 \times 10^{-11}$ \\
$3.30 \times 10^{-11}$ & $2.7182 \times 10^{-11}$ & $3.2143 \times 10^{-11}$ & $3.7104 \times 10^{-11}$ \\
$3.30 \times 10^{-11}$ & $2.7731 \times 10^{-11}$ & $3.2692 \times 10^{-11}$ & $3.7653 \times 10^{-11}$ \\
$3.30 \times 10^{-11}$ & $2.7365 \times 10^{-11}$ & $3.2326 \times 10^{-11}$ & $3.7287 \times 10^{-11}$ \\
$3.30 \times 10^{-11}$ & $2.7439 \times 10^{-11}$ & $3.2400 \times 10^{-11}$ & $3.7361 \times 10^{-11}$ \\
$3.30 \times 10^{-11}$ & $2.8655 \times 10^{-11}$ & $3.3616 \times 10^{-11}$ & $3.8577 \times 10^{-11}$ \\
$3.30 \times 10^{-11}$ & $2.8022 \times 10^{-11}$ & $3.2983 \times 10^{-11}$ & $3.7944 \times 10^{-11}$ \\
$4.40 \times 10^{-11}$ & $4.0054 \times 10^{-11}$ & $4.5015 \times 10^{-11}$ & $4.9976 \times 10^{-11}$ \\
$4.40 \times 10^{-11}$ & $3.9051 \times 10^{-11}$ & $4.4012 \times 10^{-11}$ & $4.8973 \times 10^{-11}$ \\
$4.40 \times 10^{-11}$ & $3.8239 \times 10^{-11}$ & $4.3200 \times 10^{-11}$ & $4.8161 \times 10^{-11}$ \\
$5.00 \times 10^{-11}\left(^{*}\right)$ & $5.0939 \times 10^{-11}$ & $5.5900 \times 10^{-11}$ & $6.0861 \times 10^{-11}$ \\
$5.00 \times 10^{-11}$ & $4.8077 \times 10^{-11}$ & $5.3038 \times 10^{-11}$ & $5.7999 \times 10^{-11}$ \\
$5.00 \times 10^{-11}\left(^{*}\right)$ & $3.9439 \times 10^{-11}$ & $4.4400 \times 10^{-11}$ & $4.9361 \times 10^{-11}$ \\
\hline
\end{tabular}

Table 7 - Statistical evaluation of $\sigma$ property estimated for GPR modeled data with $1 \%$ of random noise considering $97 \%$ confidence interval. $\left(^{*}\right)$ indicates that values are outside $97 \%$ confidence interval. Lower and Upper limits represent the lowermost and uppermost estimated value according inversion technique.

\begin{tabular}{|c|c|c|c|}
\hline $\begin{array}{c}\text { Real value } \\
(\sigma)\end{array}$ & $\begin{array}{c}\text { Lower } \\
\text { limit }\end{array}$ & $\begin{array}{c}\text { Mean estimated } \\
\text { value }\end{array}$ & $\begin{array}{c}\text { Upper } \\
\text { limit }\end{array}$ \\
\hline $1.40 \times 10^{-2}$ & $5.2635 \times 10^{-3}$ & $1.1375 \times 10^{-2}$ & $1.7487 \times 10^{-2}$ \\
$1.40 \times 10^{-2}$ & $5.1385 \times 10^{-3}$ & $1.1250 \times 10^{-2}$ & $1.7362 \times 10^{-2}$ \\
$1.40 \times 10^{-2}$ & $1.0138 \times 10^{-2}$ & $1.6250 \times 10^{-2}$ & $2.2362 \times 10^{-2}$ \\
$1.40 \times 10^{-2}$ & $1.0763 \times 10^{-2}$ & $1.6875 \times 10^{-2}$ & $2.2987 \times 10^{-2}$ \\
$1.40 \times 10^{-2}$ & $1.1638 \times 10^{-2}$ & $1.7750 \times 10^{-2}$ & $2.3862 \times 10^{-2}$ \\
$1.40 \times 10^{-2}$ & $1.1388 \times 10^{-2}$ & $1.7500 \times 10^{-2}$ & $2.3612 \times 10^{-2}$ \\
$1.40 \times 10^{-2}$ & $9.3885 \times 10^{-3}$ & $1.5500 \times 10^{-2}$ & $2.1612 \times 10^{-2}$ \\
$4.00 \times 10^{-3}$ & $1.3470 \times 10^{-5}$ & $6.1250 \times 10^{-3}$ & $1.2237 \times 10^{-2}$ \\
$4.00 \times 10^{-3}$ & $2.6347 \times 10^{-4}$ & $6.3750 \times 10^{-3}$ & $1.2487 \times 10^{-2}$ \\
$4.00 \times 10^{-3}$ & $3.8847 \times 10^{-4}$ & $6.5000 \times 10^{-3}$ & $1.2612 \times 10^{-2}$ \\
$3.00 \times 10^{-2}$ & $1.8513 \times 10^{-2}$ & $2.4625 \times 10^{-2}$ & $3.0737 \times 10^{-2}$ \\
$3.00 \times 10^{-2}\left(^{*}\right)$ & $1.2513 \times 10^{-2}$ & $1.8625 \times 10^{-2}$ & $2.4737 \times 10^{-2}$ \\
$3.00 \times 10^{-2}\left(^{*}\right)$ & $1.2638 \times 10^{-2}$ & $1.8750 \times 10^{-2}$ & $2.4862 \times 10^{-2}$ \\
\hline
\end{tabular}

Figure 12 shows a higher variation for $\sigma$ parameter values than those shown for inversion of modeled GPR data with $1 \%$ of random noise (see Fig. 8). To approximate better estimative for $\sigma$ parameter, $\varepsilon$ parameter is fixed, and modified ACO method is repeated from 10th to 16th position. The results for the second and the last run are shown in Figure 13.
Tables 8 and 9 provide an evaluation of the degree of convergence of $\varepsilon$ and $\sigma$ parameters. It is important to note, however, that values for $\sigma$ parameter show more dispersion than those obtained from inversion of model GPR data with $1 \%$ of random noise. These statistical analyses show that estimated values agree with true (real, synthetic) values determined for 


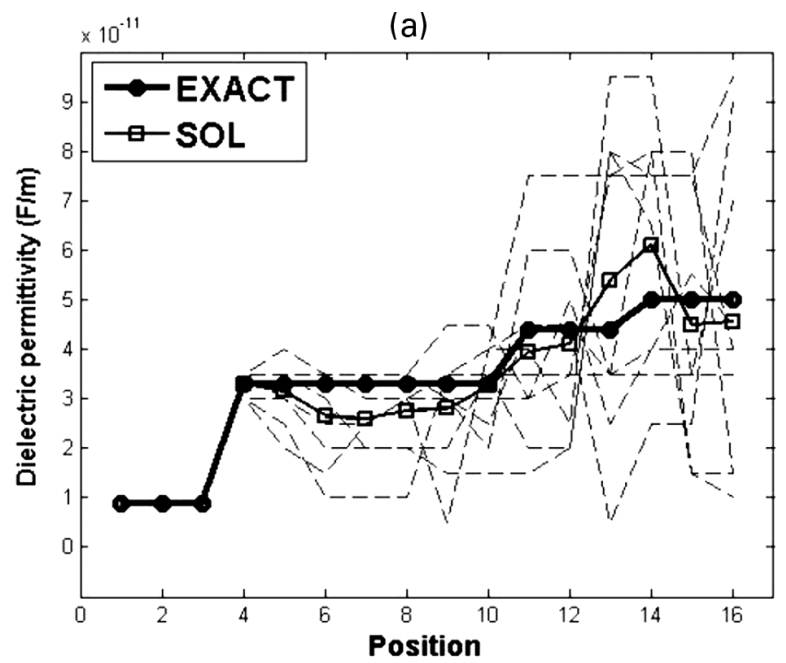

(b)

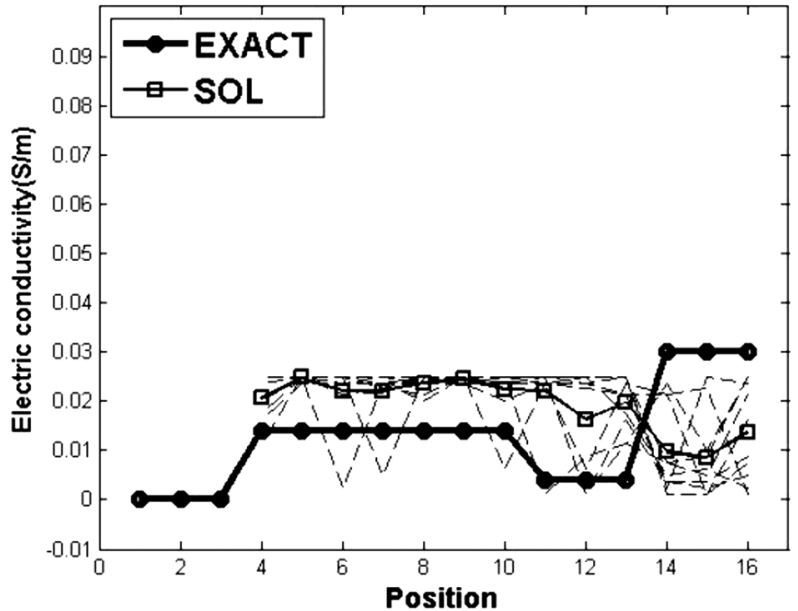

Figure 10 - Simultaneous estimated values for $\varepsilon$ (a) and $\sigma$ (b) parameters using ACO algorithm compared with model GPR data. Results after 500 iterations and minimum entropy regularization criterion, applied on GPR data with $5 \%$ random noise. EXACT refers to original value used in generating synthetic data (Real value in Fig. 1). SOL refers to estimated value from inversion technique (estimated value on Tables 8 and 9).
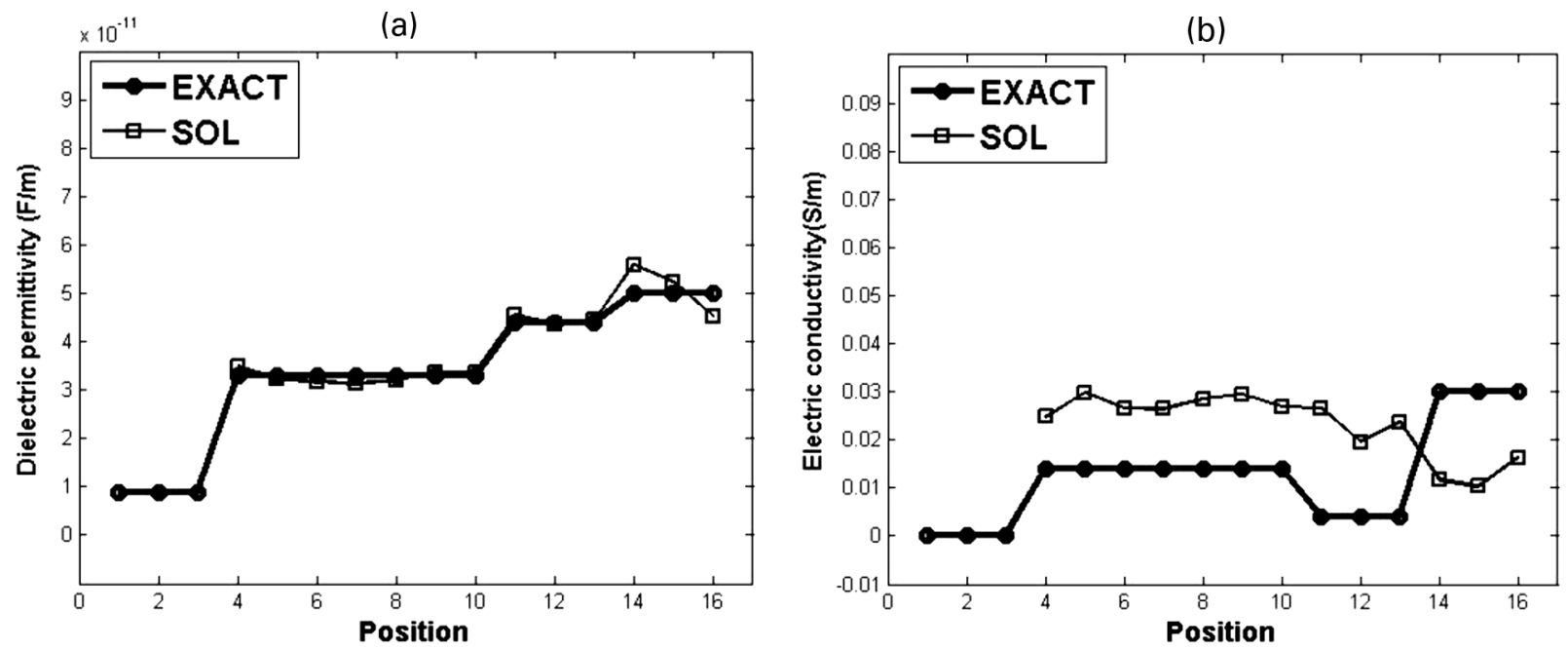

Figure 11 - Simultaneously estimated values for $\varepsilon$ (a) and $\sigma$ (b) parameters, considering the ACO results (Fig. 10) as an "initial guess" for Quasi-Newton method. Modeled GPR data with $5 \%$ of random noise. EXACT refers to original value used in generating synthetic data (Real value in Fig. 1). SOL refers to estimated value from inversion technique (estimated value on Tables 8 and 9).

generating synthetic data. However, the estimated $\varepsilon$ and $\sigma$ parameters for deepest positions do not agree with real values in the $97 \%$ confidence interval, and this aspect will be addressed later in the paper.

\section{CONCLUSIONS}

The ACO and Quasi-Newton inversion techniques produced good results in reconstructing both the dielectric permittivity $(\varepsilon)$ and electric conductivity $(\sigma)$ from synthetic ground-penetrating radar data. The simultaneous estimation of $\varepsilon$ and $\sigma$ parameters were not tried up this date, and could only be accomplished when GPR data from three different frequency sources $(800$, 1000 and $1200 \mathrm{MHz}$ ) was taken into account. This is particularly important since previous estimations considers only dielectric permittivity $(\varepsilon)$ to derived velocity for GPR data, and, then, a series of geotechnical and geological properties of the underground media. In this way, the paper presents new procedures to determine velocity (see Eq. (1)), and to derive dielectric permittivity $(\varepsilon)$ and electric conductivity $(\sigma)$ maps from GPR surveys data. 


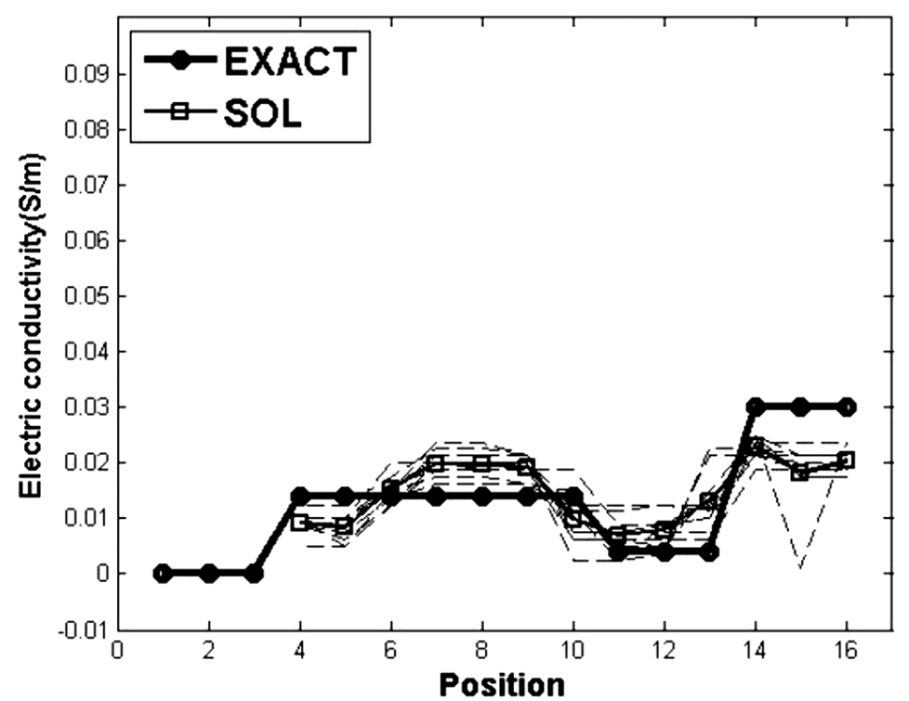

Figure 12 - Estimated values for $\sigma$ parameter after running the modified ACO algorithm (first run), and considering the fixed $\varepsilon$ values. GPR modeled data with $5 \%$ of random noise. EXACT refers to original value used in generating synthetic data (Real value in Fig. 1). SOL refers to estimated value from inversion technique (estimated value on Tables 8 and 9).

(a)

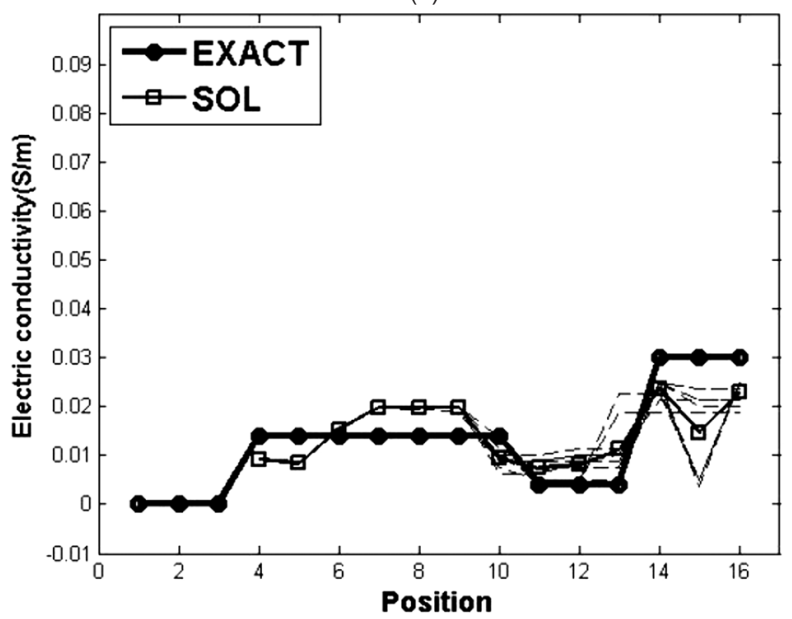

(b)

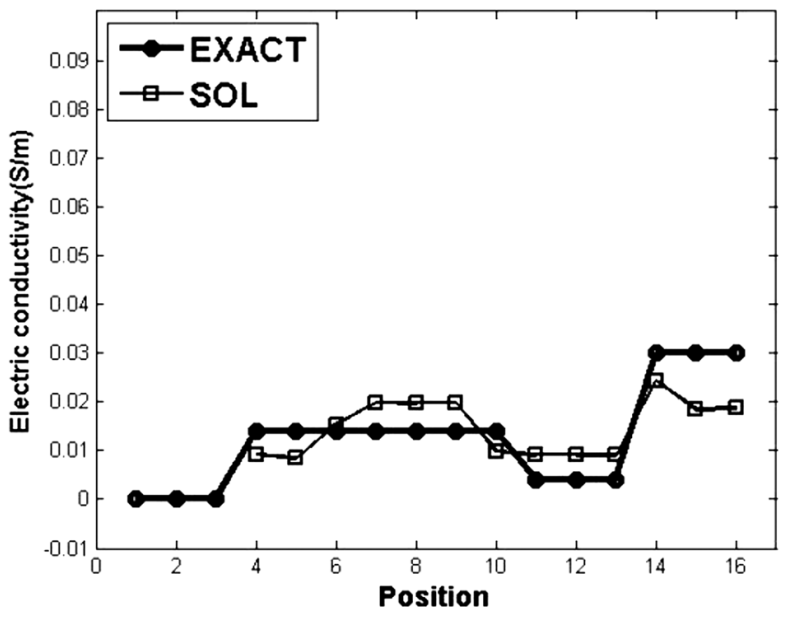

Figure 13 - Estimated values for $\sigma$ parameter using the modified ACO inversion algorithm. The conductivity is fixed (a) from 4th to 9th position in the second run, and (b) from 4th to 15th position for the last run. GPR modeled data with $5 \%$ of random noise. EXACT refers to original value used in generating synthetic data (Real value in Fig. 1). SOL refers to estimated value from inversion technique (estimated value on Tables 8 and 9).

The ACO inversion technique is a time-consuming process. However, it demonstrated to be a very good technique for a first and simultaneous estimation of both $\varepsilon$ and $\sigma$ parameters. It worked well even though the initial values introduced for those parameters are far from real values $[11]^{\top}$. The classical ACO inversion algorithm was here modified to estimate two variables at the same time: dielectric permittivity $(\varepsilon)$ and electric conductivity $(\sigma)$, according Table 2 algorithms.

The Quasi-Newton technique, on the other hand, demon- strated to produce good solutions from mean values obtained from ACO inversion. This technique did not work when initial values of the variables are set far from their real values. However, when initial values to estimate are close to real, it saves much processing time compared to ACO technique. Then, it can be applied to refine estimations as close as possible.

The electric conductivity $(\sigma)$ is the most difficult variable to be estimated from synthetic GPR data. The ACO technique was modified to keep $\varepsilon$ parameter constant and to estimate $\sigma$ values 
Table 8 - Statistical evaluation of $\varepsilon$ property estimated for GPR modeled data with $5 \%$ of random noise considering $97 \%$ confidence interval. $\left({ }^{*}\right)$ indicates that values are outside $97 \%$ confidence interval. Lower and Upper limits represent the lowermost and uppermost estimated value according inversion technique.

\begin{tabular}{|c|c|c|c|}
\hline $\begin{array}{c}\text { Real values } \\
(\varepsilon)\end{array}$ & $\begin{array}{c}\text { Lower } \\
\text { limit }\end{array}$ & $\begin{array}{c}\text { Mean estimated } \\
\text { value }\end{array}$ & $\begin{array}{c}\text { Upper } \\
\text { limit }\end{array}$ \\
\hline $3.30 \times 10^{-11}$ & $2.9767 \times 10^{-11}$ & $3.4728 \times 10^{-11}$ & $3.9689 \times 10^{-11}$ \\
$3.30 \times 10^{-11}$ & $2.7227 \times 10^{-11}$ & $3.2188 \times 10^{-11}$ & $3.7149 \times 10^{-11}$ \\
$3.30 \times 10^{-11}$ & $2.6839 \times 10^{-11}$ & $3.1800 \times 10^{-11}$ & $3.6761 \times 10^{-11}$ \\
$3.30 \times 10^{-11}$ & $2.6239 \times 10^{-11}$ & $3.1200 \times 10^{-11}$ & $3.6161 \times 10^{-11}$ \\
$3.30 \times 10^{-11}$ & $2.7154 \times 10^{-11}$ & $3.2115 \times 10^{-11}$ & $3.7076 \times 10^{-11}$ \\
$3.30 \times 10^{-11}$ & $2.8639 \times 10^{-11}$ & $3.3600 \times 10^{-11}$ & $3.8561 \times 10^{-11}$ \\
$3.30 \times 10^{-11}$ & $2.8743 \times 10^{-11}$ & $3.3704 \times 10^{-11}$ & $3.8665 \times 10^{-11}$ \\
$4.40 \times 10^{-11}$ & $4.0462 \times 10^{-11}$ & $4.5423 \times 10^{-11}$ & $5.0384 \times 10^{-11}$ \\
$4.40 \times 10^{-11}$ & $3.8453 \times 10^{-11}$ & $4.3414 \times 10^{-11}$ & $4.8375 \times 10^{-11}$ \\
$4.40 \times 10^{-11}$ & $3.9398 \times 10^{-11}$ & $4.4359 \times 10^{-11}$ & $4.9320 \times 10^{-11}$ \\
$5.00 \times 10^{-11}\left(^{*}\right)$ & $5.0861 \times 10^{-11}$ & $5.5822 \times 10^{-11}$ & $6.0783 \times 10^{-11}$ \\
$5.00 \times 10^{-11}$ & $4.7300 \times 10^{-11}$ & $5.2261 \times 10^{-11}$ & $5.7222 \times 10^{-11}$ \\
$5.00 \times 10^{-11}$ & $4.0253 \times 10^{-11}$ & $4.5214 \times 10^{-11}$ & $5.0175 \times 10^{-11}$ \\
\hline
\end{tabular}

Table $\mathbf{9}$ - Statistical evaluation of $\sigma$ property estimated for GPR modeled data with $5 \%$ of random noise considering $97 \%$ confidence interval. $\left({ }^{\star}\right)$ indicates that values are outside 97\% confidence interval. Lower and Upper limits represent the lowermost and uppermost estimated value according inversion technique.

\begin{tabular}{|c|c|c|c|}
\hline $\begin{array}{c}\text { Real value } \\
(\sigma)\end{array}$ & $\begin{array}{c}\text { Lower } \\
\text { limit }\end{array}$ & $\begin{array}{c}\text { Mean estimated } \\
\text { value }\end{array}$ & $\begin{array}{c}\text { Upper } \\
\text { limit }\end{array}$ \\
\hline $1.40 \times 10^{-2}$ & $3.1385 \times 10^{-3}$ & $9.2500 \times 10^{-3}$ & $1.5362 \times 10^{-2}$ \\
$1.40 \times 10^{-2}$ & $2.2635 \times 10^{-3}$ & $8.3750 \times 10^{-3}$ & $1.4487 \times 10^{-2}$ \\
$1.40 \times 10^{-2}$ & $9.2635 \times 10^{-3}$ & $1.5375 \times 10^{-2}$ & $2.1487 \times 10^{-2}$ \\
$1.40 \times 10^{-2}$ & $1.3763 \times 10^{-2}$ & $1.9875 \times 10^{-2}$ & $2.5987 \times 10^{-2}$ \\
$1.40 \times 10^{-2}$ & $1.3638 \times 10^{-2}$ & $1.9750 \times 10^{-2}$ & $2.5862 \times 10^{-2}$ \\
$1.40 \times 10^{-2}$ & $1.3638 \times 10^{-2}$ & $1.9750 \times 10^{-2}$ & $2.5862 \times 10^{-2}$ \\
$1.40 \times 10^{-2}$ & $3.7635 \times 10^{-3}$ & $9.8750 \times 10^{-3}$ & $2.5987 \times 10^{-2}$ \\
$4.00 \times 10^{-3}$ & $3.0135 \times 10^{-3}$ & $9.1250 \times 10^{-3}$ & $1.5237 \times 10^{-2}$ \\
$4.00 \times 10^{-3}$ & $3.0135 \times 10^{-3}$ & $9.1250 \times 10^{-3}$ & $1.5237 \times 10^{-2}$ \\
$4.00 \times 10^{-3}$ & $2.8885 \times 10^{-3}$ & $9.0000 \times 10^{-3}$ & $1.5112 \times 10^{-2}$ \\
$3.00 \times 10^{-2}$ & $1.8138 \times 10^{-2}$ & $2.4250 \times 10^{-2}$ & $3.0362 \times 10^{-2}$ \\
$3.00 \times 10^{-2}\left(^{*}\right)$ & $1.2263 \times 10^{-2}$ & $1.8375 \times 10^{-2}$ & $2.4487 \times 10^{-2}$ \\
$3.00 \times 10^{-2}\left(^{*}\right)$ & $1.2638 \times 10^{-2}$ & $1.8750 \times 10^{-2}$ & $2.4862 \times 10^{-2}$ \\
\hline
\end{tabular}

for the deepest positions on the objective function, as shown in Table 2. This procedure led to well fitted results for both electrical properties.

The estimated values for both $\varepsilon$ and $\sigma$ parameters showed to fit closer to the initial/real values even when random noise was introduced into synthetic GPR data. These results seem to be due to error propagation in synthetic GPR data generation through FDTD. It is to be remembered that error propagation is time dependent in explicit methods, such as FDTD (Vilhena et al., 2008; Tirabassi et al., 2009). Then, deviation of estimated dielectric 
permittivity $(\varepsilon)$ and electric conductivity $(\sigma)$ values from real/initial values in deepest positions is a consequence of synthetic GPR data modeling (FDTD). This will not be the case when applying $\mathrm{ACO}$ and Quasi-Newton inversion techniques directly on surveyed GPR data.

The obtained results open new perspectives in processing multichannel GPR data. The ACO and Quasi-Newton inversion techniques can be applied for mapping dielectric permittivity and electric conductivity distribution in the subsurface, and also are important parameters to determine a number of physical properties of the geological and geotechnical media through which EM waves propagate. Mapping $\varepsilon$ and $\sigma$ distribution can be applied for environmental purposes, such as contamination plume control, or for high-way and rail-road applications.

\section{APPENDIX}

\section{DIRECT MODEL}

The governing Maxwell equations for GPR direct modeling are:

$$
\begin{aligned}
& \nabla \times \vec{E}=-\frac{\partial \vec{B}}{\partial t}-\frac{\rho^{\prime}}{\mu} \vec{B} \\
& \nabla \times \vec{H}=-\frac{\partial \vec{D}}{\partial t}+\frac{\sigma}{\varepsilon} \vec{D} \\
& \nabla \cdot \vec{B}=0 \\
& \nabla \cdot \vec{D}=0
\end{aligned}
$$
Gauss law for electric field (A.3) Gauss law for magnetic field (A.4)

where $\vec{E}$ is electric field vector $(\mathrm{V} / \mathrm{m}), \vec{H}$ is magnetic field vector $(\mathrm{A} / \mathrm{m}), \vec{B}$ is magnetic flux density $\left(\mathrm{Wb} / \mathrm{m}^{2}\right), \vec{D}$ is electric flux density $\left(\mathrm{C} / \mathrm{m}^{2}\right), \varepsilon$ is dielectric permittivity $(\mathrm{F} / \mathrm{m}), \mu$ is magnetic permeability $(H / m), \sigma$ is electric conductivity $(\mathrm{S} / \mathrm{m})$, and $\rho^{\prime}$ is equivalent magnetic resistivity $(\Omega / m)$.

For isotropic and non-dispersive materials, the following relationships are valid:

$$
\begin{gathered}
\vec{B}=\mu \vec{H} \\
\vec{D}=\varepsilon \vec{E} \\
\frac{\partial \vec{H}}{\partial t}=-\frac{1}{\mu} \nabla \times \vec{E}-\frac{\rho^{\prime}}{\mu} \vec{H} \\
\frac{\partial \vec{E}}{\partial t}=-\frac{1}{\varepsilon} \nabla \times \vec{H}-\frac{\sigma}{\varepsilon} \vec{E}
\end{gathered}
$$

In 1-D modeling considered here, the EMw propagated in the $x$ direction, since GPR antennas could be disposed in a number of arrays (antenna parallel to profile survey). The Maxwell equations were then simplified to coordinates in the transverse electric (TE) mode (Taflove, 1995, p. 57):

$$
\begin{gathered}
\frac{\partial E_{x}}{\partial t}=\frac{1}{\varepsilon}\left(-\sigma E_{x}\right) \\
\frac{\partial E_{y}}{\partial t}=\frac{1}{\varepsilon}\left(-\frac{\partial H_{z}}{\partial x}-\sigma E_{y}\right) \\
\frac{\partial H_{z}}{\partial t}=\frac{1}{\mu}\left(-\frac{\partial E_{y}}{\partial x}-\rho^{\prime} H_{z}\right)
\end{gathered}
$$

Assuming that initial field conditions are null

$$
\left(E_{x}(t=0)=0\right),
$$

Eq. (A.9) is $\frac{\partial E_{x}}{\partial t}=0$. Then, two equations can be written in TE mode:

$$
\begin{aligned}
\frac{\partial E_{y}}{\partial t} & =\frac{1}{\varepsilon}\left(-\frac{\partial H_{z}}{\partial x}-\sigma E_{y}\right) \\
\frac{\partial H_{z}}{\partial t} & =\frac{1}{\mu}\left(-\frac{\partial E_{y}}{\partial x}-\rho^{\prime} H_{z}\right)
\end{aligned}
$$

\section{FDTD Numerical Modeling of Electromagnetic Wave Propagation}

FDTD modeling is an explicit method, such that the forward values of the EM wave take into account the previous ones. It is based on time-domain Maxwell equations for isotropic media, according to solutions proposed by Yee (1966). Vieira (2003) expanded Yee's (1966) solution for 2-D EMw propagation in geological, multilayer conditions, according to C++ codes (Rodríguez, 2001; Bulla, 2006). Recently, Irving \& Knight (2006) presented a FDTD numerical modeling for EMw propagation in the 2-D geological space.

Numerical modeling performed in this work was adapted from Rodríguez (2001), Vieira (2003) and Bulla (2006) algorithms. The program codes were, however, written in FORTRAN-90 programming language. The numerical modeling was performed in 1-D space to avoid diffractions of EMw in the first moment.

Taking into account Eqs. (A.12) and (A.13) and substituting finite differences in time and space domains, the following system was derived (Taflove, 1995; Sections 3.6.3-3.6.5):

$$
\begin{gathered}
\left.E_{y}\right|_{i} ^{n+1}=\left.C_{a}(m) E_{y}\right|_{i} ^{n} \\
+C_{b_{1}}(m)\left(\left.H_{z}\right|_{i} ^{n+\frac{1}{2}}-\left.H_{z}\right|_{i-1} ^{n+\frac{1}{2}}\right) \\
\left.H_{z}\right|_{i} ^{n+1}=\left.D_{a}(m) H_{z}\right|_{i} ^{n} \\
+D_{b_{1}}(m)\left(\left.E_{y}\right|_{i+1} ^{n+1}-\left.E_{y}\right|_{i} ^{n+1}\right)
\end{gathered}
$$




$$
\begin{aligned}
\left.C_{a}\right|_{i} & =\frac{\left(1-\frac{\sigma_{i} \Delta t}{2 \cdot \varepsilon_{i}}\right)}{\left(1+\frac{\sigma_{i} \Delta t}{2 \cdot \varepsilon_{i}}\right)} \\
\left.C_{b_{1}}\right|_{i} & =\frac{\left(\frac{\Delta t}{\varepsilon_{i} \Delta x}\right)}{\left(1+\frac{\sigma_{i} \Delta t}{2 \cdot \varepsilon_{i}}\right)} \\
\left.D_{a}\right|_{i} & =\frac{\left(1-\frac{\rho_{i}^{\prime} \Delta t}{2 \cdot \mu_{i}}\right)}{\left(1+\frac{\rho_{i}^{\prime} \Delta t}{2 \cdot \mu_{i}}\right)} \\
\left.D_{b_{1}}\right|_{i} & =\frac{\left(\frac{\Delta t}{\mu_{i} \Delta x}\right)}{\left(1+\frac{\rho_{i}^{\prime} \Delta t}{2 \cdot \mu_{i}}\right)}
\end{aligned}
$$

where $m$ is matrix representing geological model, $\Delta t$ is time increment and $\Delta x$ is space increment.

Equations (A.14) and (A.15) were used to compute EMw propagation in the geological model (Fig. 1). The EM source was a bandpass Gaussian pulse with Fourier spectrum symmetrical about $f$ to approximate the GPR pulse (Taflove, 1995; p. 110), where $f$ is input data in code FDTD.

The code program was improved with absorbing boundaries to avoid reflections from model edges and multiple reflections, to determine reflection coefficients and attenuations as well as amplitude of $\vec{E}$ and $\vec{H}$ in any geological model coordinate. Since the simulation was performed in 1-D space, it was supposed that EMw show only $E_{y}$ and $H_{z}$, and that it propagates in $x$ direction; it was also assumed that the time increment was $\Delta t=\Delta x / c$, where $c$ is speed of light in vacuum, the maximum time for stability conditions. Then, considering that the network extended from $x=0$ to $x=j \Delta x$, the conditions for truncating $E_{y}$ component at boundaries were:

$$
\begin{gathered}
E_{y}^{n}(0)=E_{y}^{n-1}(1) \\
E_{y}^{n}(j)=E_{y}^{n-1}(j-1)
\end{gathered}
$$

Eqs. (A.20) and (A.21) simulate EMw propagation in a free numerical domain that may be truncated at given positions. Eq. (A.20) is an absorbing boundary similar to that proposed by Mür (1981); however, it requires less computational efforts than PML (Perfect Matched Layer), since 1-D space EMw propagation was applied in this study.

\section{Numerical stability and dispersion}

The FDTD algorithm can cause dispersion errors of the propagating waves on the net formed with the Yee cells (1966). Dispersion may be defined as the phase speed variation from spectral components of a wave during its propagation. Dispersion errors caused by the algorithm may vary with wavelength, direction of propagation and discretization of the grid.

Therefore, the choice of spatial increment $(\Delta x)$ is motivated by precision reasons (Taflove, 1995). In order to guarantee the precision of values from calculated fields, $\Delta x$ must be chosen as a fraction smaller than the thinnest dimension of the spreader object, and also as a fraction of the smallest wavelength $(\lambda)$. Thus, the field values do not vary between the consecutive points of the grid in a significant way. The values used for the largest spatial discretization are between $\lambda / 10 \leq \Delta x \leq \lambda / 20$. Furthermore, to avoid numerical instabilities, the FDTD algorithm requires temporal increment $\Delta t$ to be related with spatial increment $\Delta x$ in the following way:

$$
\Delta t \leq \frac{\Delta x}{c}
$$

This relation must be achieved in order for the FDTD algorithm to converge during iterations.

\section{ACKNOWLEDGEMENTS}

The authors thank FAPERGS (Proc. 04/0677.8 PCOR), CNPq (Proc. 476692/2011-3) and Universidade Feevale for their partial financial support of this work. Critical reviews by anonymous reviewers contributed to the final version of the manuscript.

\section{REFERENCES}

BANGBING W, GANG T, BO S, JINXUE G \& XIANGPEIZ. 2006. An analysis of the multi-fold method for GPR exploration. Applied Geophysics, 3: 187-191

BRADFORD JH. 2006. Applying reflection tomography in the post migration domain to multifold ground-penetrating radar data. Geophysics, 71: K1-K8.

BRADFORD JH. 2008. Measuring water content heterogeneity using multifold GPR with reflection tomography. Vadoze Zone Journal, 7: 184193.

BULLA G. 2006. Cálculo de taxa de absorção especíica e aumento de temperatura em modelos de cabeça de adulto e criança. Master Dissertation on Engineering - Programa de Pós-Graduação em Engenharia Elétrica, Universidade Federal do Rio Grande do Sul, 2006. 96 pp. 
CAMPOS VELHO HF \& RAMOS FM. 1997. Numerical inversion of twodimensional geoelectric conductivity distributions from magnetotelluric data. Brazilian Journal of Geophysics, 15(2): 133-144.

CAMPOS VELHO HF, RAMOS FM, CHALHOUB ES, STEPHANY S, CARVALHO OC \& SOUZA FL. 2007. Inverse problems in space science and technology. Inverse Problems in Science and Engineering, 15(4): 359-372.

CASSIDY NJ. 2009. Electrical and magnetic properties of rocks, soils and fluids. In: JOL HM (Ed.). Ground penetrating radar: theory and applications. Elsevier Science Publ., Netherlands, Chapter 2, p. 41-72.

DAVIS JL \& ANNAN AP. 1989. Ground-penetrating radar for highresolution mapping of soil and rock stratigraphy. Geophysical Prospecting, 37: 531-551.

DAVIS JL, ROSSITER JT, MESHER DE \& DAWLEY CB. 1994. Quantitative measurements of pavement structures using radar. In: International Conference on Ground Penetrating Radar, 5., Proceedings... Kitchener, Ontario, Canada, 1994, p. 319-334.

DENNIS JE \& SCHNABEL RB. 1983. Numerical methods for unconstrained optimization and nonlinear equations. Englewood Cliffs, N.J., Prentice-Hall, xiii, includes index. 378 pp.

DORIGO M, MANIEZZO V \& COLORNI A. 1996. The ant optimization: optimization by a colony of cooperating agents. IEEE Transactions on Systems, Man, and Cybernetics - Part B Cybernetics, 26(1): 29-41.

FISHER E, McMECHAN GA \& ANNAN AP. 1992. Acquisition and processing of wide-aperture ground-penetrating radar data. Geophysics, 57 : 495-504.

FLETCHER R. 1987. Practical Methods of Optimization. 2nd ed., London, England: John Wiley \& Sons, 436 pp.

GERHARDS H, WOLLSCHLÄGERU, YU Q, SCHIWEK P, PAN X \& ROTH K. 2008. Continuous and simultaneous measurement of reflector depth and average soil-water content with multichannel ground-penetrating radar. Geophysics, 73: J15-J23.

GOMES MG. 2010. Simulação e inversão de ondas eletromagnéticas em diferentes meios geológico-geotécnicos. Doctorate thesis on Engineering - Programa de Pós-Graduação em Engenharia de Minas, Metalúrgica e de Materiais, Universidade Federal do Rio Grande do Sul, 2010.119 pp.

IRVING J \& KNIGHT R. 2006. Numerical modeling of ground-penetrating radar in 2-D using MATLAB. Computers \& Geosciences, 32: 12471258.

LAMM PK. 1993. Inverse problems and ill-posedness. In: ZABARAS N, WOODBURY KA \& RAYNAUD M (Eds.). Inverse Problems in Engineering: Theory and Practice. Palm Coast: ASME, p. 1-10.

LUTZ P \& PERROUD H. 2006. Phased-array transmitters for GPR. Journal of Geophysics and Engineering, 3: 35-42.
MANACORDA G, MORANDI D, SPARRI A \& STACCONE G. 2002. A customized GPR system for railroad tracks verification. In: International Conference on Ground Penetrating Radar, 9., Santa Barbara, CA, April 29-May 2, 2002. Proceedings SPIE, 4758: 719-723.

MÜR G. 1981. Absorbing boundary conditions for the finite-difference approximation of the time-domain electromagnetic field equations. Electromagnetic Compatibility - IEEE Transactions, 23: 377-382.

PAASCHE H, WENDRICH A, TRONICKE J \& TRELA C. 2008. Detecting voids in masonry by cooperatively inverting $P$-wave and georadar traveltimes. Journal of Geophysics and Engineering, 5: 256-267.

PARASNIS DS. 1997. Principle of Applied Geophysics. 5th ed., London, England: Chapman \& Hall, 437 pp.

RODRÍGUEZ CEF. 2001. Efeitos biológicos das radiações de rádio frequências de telefonia celular: simulação FDTD. Master Dissertation on Engineering, Programa de Pós-Graduação em Engenharia Elétrica, Universidade Federal do Rio Grande do Sul, 2001. 118 pp.

SAARENKETO T. 2009. NDT transportation. In: JOL HM (Ed.). Ground penetrating radar: theory and applications. Elsevier Science Publ., Netherlands, Chapter 13, p. 395-444.

SOUTO RP, STEPHANY S, BECCENERI JC, CAMPOS VELHO HF \& SILVA NETO AJ. 2005. Reconstruction of a spatial dependent scattering albedo in a radiative transfer problem using a hybrid ant colony system implementation and a pre-regularization scheme. In: World Congress on Structural and Multidisciplinary Optimization, 6., Proceedings... Rio de Janeiro, RJ, Brazil, 2005. Paper 3941. 9 pp.

SOUTO RP, CAMPOS VELHO HF \& STEPHANY JS. 2006. Reconstruction of vertical profiles of the absorption and scattering coefficients from multispectral radiances. Mathematics and Computers in Simulations, 73: 255-267.

SOUTO RP, BARBOSA VCF, CAMPOS VELHO HF \& STEPHANY JS. 2007. Determining chlorophyll concentration in offshore sea water from multi-spectral radiances by using second derivative criterion and ant colony meta-heuristic. In: Inverse Problems, Design and Optimization Symposium, Proceedings... Miami, Florida, USA, 16-18 April 2007. p. 341-348.

STRICKEL M, TAFLOVE A \& UMASHANKAR K. 1994. Finite-difference time-domain formulation of an inverse-scattering scheme for remote sensing of conducting and dielectric targets Part II - Two dimensional case. Journal of Electromagnetic Waves and Applications, 8(4): 509529.

TAFLOVE A. 1995. Computational Electrodynamics: the finite-difference time-domain method 1st Edition Artech House Inc., London: England, 599 pp.

TIKHONOV AN \& ARSENIN VY. 1977. Solutions of ill-posed. Washington, EUA: Winston and Sons, xiii + 258 pp. 
TIRABASSI T, TIESI A, BUSKE D, VILHENA MT \& MOREIRA DM. 2009. Some characteristics of plume from a point source based on analytical solution of the two-dimensional advection diffusion equation. Atmospheric Environment, 43: 2221-2227.

UMASHANKAR K, CHAUDHURI S, BARRASH W \& TAFLOVE A. 1994. Finite-difference time-domain formulation of an inverse-scattering scheme for remote sensing of inhomogeneous lossy layered media, Part I - One dimensional case. Journal of Electromagnetic Waves and Applications, 8(4): 489-508.

VIEIRA JS. 2003. Estudo de propagação de onda eletromagnética em estrutura geológica estratificada. Master Dissertation on Engineering, Programa de Pós-Graduação em Engenharia de Minas, Metalúrgica e de Materiais, Universidade Federal do Rio Grande do Sul, 2003. 159 pp.

VILHENA MT, COSTA CP, MOREIRA DM \& TIRABASSI T. 2008. A semi- analytical solution for the three-dimensional advection-diffusion equation considering non-local turbulence closure. Atmospheric Research, 90: 63-69.

WESTERMANN S, WOLLSCHLÄGER U \& BOIKE J. 2010. Monitoring of active layer dynamics at a permafrost site on Svalbard using multichannel ground-penetrating radar. The Cryosphere, 4: 475-487.

WOLLSCHLÄGER U, GERHARDS H, YU Q \& ROTH K. 2010. Multichannel ground-penetrating radar to explore spatial variations in thaw depth and moisture content in the active layer of permafrost site. The Cryosphere, 4: 269-283.

YEE K. 1966. Numerical solution of initial boundary value problems involving Maxwell's equations in isotropic media. IEEE Transactions on Antennas and Propagation, 14(5): 302-307.

Recebido em 19 abril, 2013 / Aceito em 30 julho, 2014

Received on April 19, 2013 / Accepted on July 30, 2014

\section{NOTES ABOUT THE AUTHORS}

Maria da Graça Gomes. B.Sc. in Mathematics from Universidade Federal do Rio Grande do Sul (1997), M.Sc. in Applied Mathematics from the Universidade Federal do Rio Grande do Sul (1999), Ph.D. in Mining, Metallurgical and Materials Engineering, from the Universidade Federal do Rio Grande do Sul (2010). Currently, is a professor at Universidade Feevale. Experienced in Mathematics and Statistics, working especially with the following topics: matrix inverse, discrete ordinates, matrix pencil, matrix algebra and numerical simulation. Works at Centro de Pesquisa e Planejamento - CPP (Feevale) (2008) as a consultant on statistical analysis research to general public, academics and professors.

Roberto Pinto Souto. Graduated with Bachelor's degree in Computational Applied Mathematics in Universidade Federal do Rio Grande do Sul (1997), graduated with master's degree in Remote Sensing by the Instituto Nacional de Pesquisas Espaciais (National Institute for Space Research) (2000); and Ph.D. in Applied Computing by the Instituto Nacional de Pesquisas Espaciais (National Institute for Space Research) (2006). Wide experience in the computer science field, with emphasis on scientific computing. Researches mainly on the following themes: high-performance processing, computational modeling and inverse problems.

Alexandre Sacco de Athayde. Bachelor's degree in applied mathematics from the Universidade Federal do Rio Grande do Sul (2006) and has Masters degree in applied mathematics from the same university (2009). Experience in the mathematics field, with emphasis on applied mathematics. Currently, is an Assistant professor at the Universidade Federal de Pelotas.

Marco Túllio Menna Barreto de Vilhena. B.Sc. in Civil Engineering from the Universidade Federal do Rio Grande do Sul (1968), M.Sc. in Applied Mathematics from the same university (1982) and Ph.D. in Mechanical Engineering from the Universidade Federal do Rio Grande do Sul (1988). Retired Full Professor and currently Invited Professor at the Graduate Program in Mechanical Engineering of the Universidade Federal do Rio Grande do Sul. Has scientific experience in applied mathematics, with emphasis on models of neutral particle transport, diffusion of neutrons in the area of physics of nuclear reactors as well as simulation of pollutant dispersion in the atmosphere.

Adelir José Strieder. Geologist graduated in 1985. Master Degree and Ph.D. in Mineral Exploration and Regional Geology at Universidade de Brasília (1989-1993). From 1994 to 2009, was Professor at UFRGS. Currently, is Professor at Centro de Engenharias (Universidade Federal de Pelotas), dealing with mineral exploration and natural resources and processes for undergraduation courses (Geological Engineering, Petroleum Engineering, and Geospatial data Processing). The main areas of research are: geological and environmental instrumentation, geological and geophysical exploration, geospatial data integration and modelling, engineering and environmental geology. Affiliated at SBGf and SEG. 